BNL-44403-98/1-Rev.

Informal Report

\title{
National Synchrotron Light Source Guidelines for the Conduct of Operations
}

\author{
Michael Buckley
}

January 1998
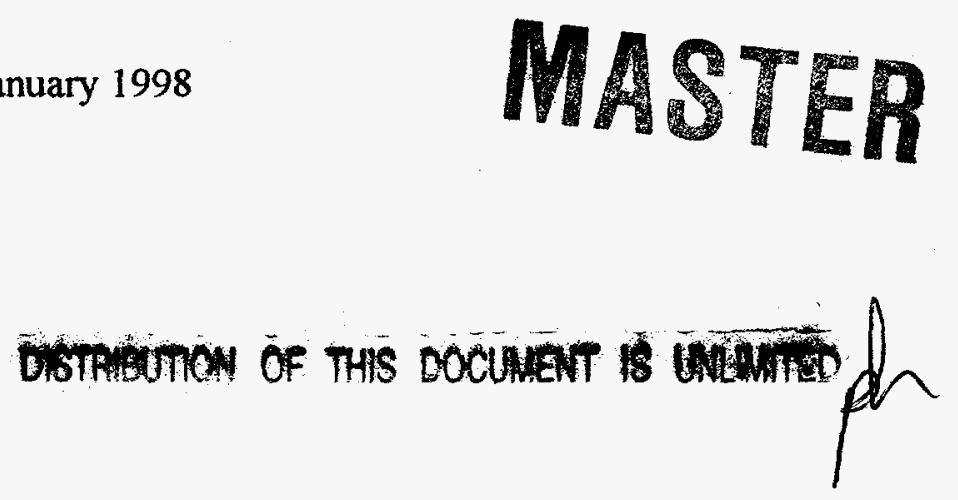

\author{
National Synchrotron Light Source \\ Brookhaven National Laboratory, \\ Upton, NY 11973 USA
}

Work performed under the auspices of the U.S. Department of Energy, under contract DE-AC02-76CH00016 


\section{DISCLAIMER}

This report was prepared as an account of work sponsored by an agency of the United States Government. Neither the United States Government nor any agency thereof, nor any of their employees, makes any warranty, express or implied, or assumes any legal liability or responsibility for the accuracy, completeness, or usefulness of any information, apparatus, product, or process disclosed, or represents that its use would not infringe privately owned rights. Reference herein to any specific commercial product, process, or service by trade name, trademark, manufacturer, or otherwise does not necessarily constitute or imply its endorsement, recommendation, or favoring by the United States Government or any agency thereof. The views and opinions of authors expressed herein do not necessarily state or reflect those of the United States Government or any agency thereof. 


\section{DISCLAIMER}

Portions of this document may be illegible electronic image products. Images are produced from the best available original document. 


\begin{tabular}{|c|c|c|c|c|}
\hline \multirow{2}{*}{\multicolumn{2}{|c|}{$\begin{array}{l}\text { Brookhaven National Laboratory } \\
\text { National Synchrotron Light Source }\end{array}$}} & $\begin{array}{l}\text { Number: } \\
\text { BNL-44403 }\end{array}$ & Revis & \\
\hline & & $\begin{array}{l}\text { Effective: } \\
\qquad 1 / 4 / 98\end{array}$ & $\begin{array}{l}\text { Page } \\
\text { of }\end{array}$ & $\begin{array}{l}1 \\
50\end{array}$ \\
\hline \multirow[t]{2}{*}{ Subject: } & \multirow[t]{2}{*}{ CONDUCT OF OPERATIONS } & \multicolumn{3}{|c|}{ Prepared By: Mrockey } \\
\hline & & \multicolumn{3}{|c|}{ Approved By: M. Hakt } \\
\hline
\end{tabular}

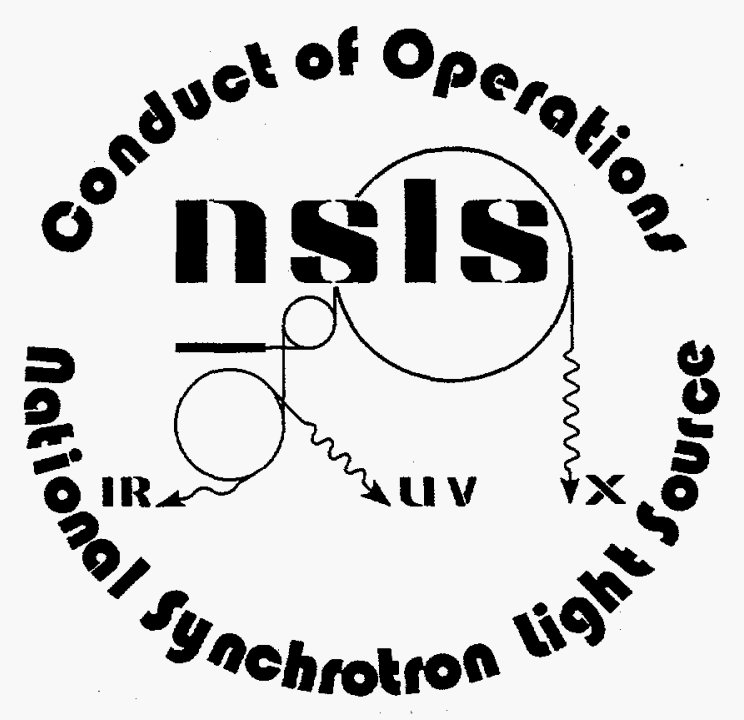




\begin{tabular}{|c|c|c|c|}
\hline \multicolumn{4}{|c|}{ CONDUCT OF OPERATIONS • NATIONAL SYNCHROTRON LIGHT SOURCE } \\
\hline Number: BNL-44403 & Revision 2 & Effective: $1 / 4 / 98$ & Page 2 of 50 \\
\hline
\end{tabular}

TABLE OF CONTENTS

INTRODUCTION

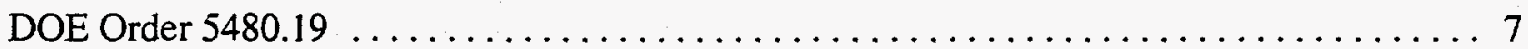

Characteristics of the National Synchrotron Light Source $\ldots \ldots \ldots \ldots \ldots \ldots \ldots \ldots .7$

CHAPTER I

OPERATIONS ORGANIZATION AND ADMINISTRATION

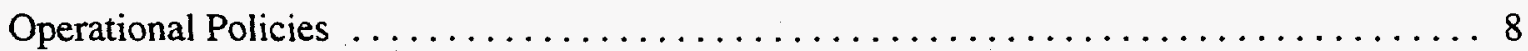

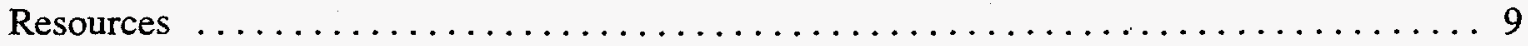

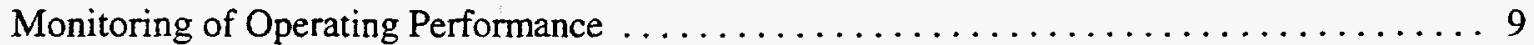

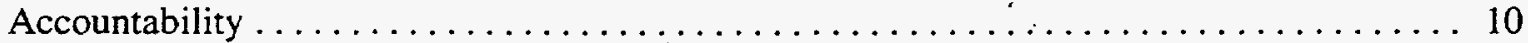

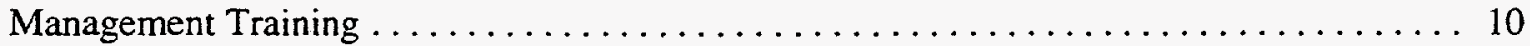

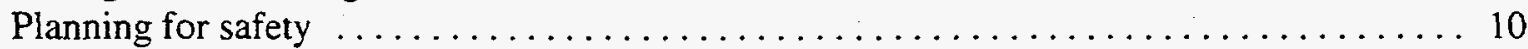

CHAPTER II

SHIFT ROUTINES \& OPERATING PRACTICES

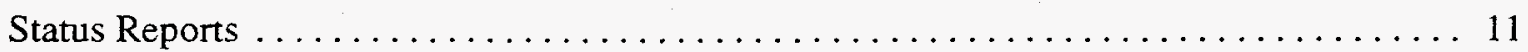

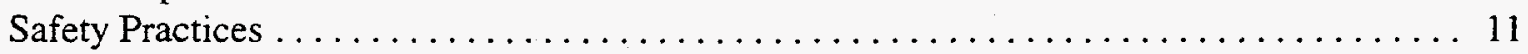

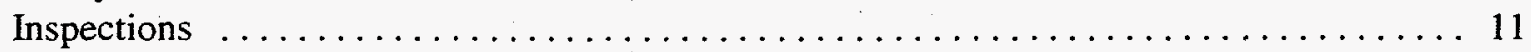

Personnel Protection $\ldots \ldots \ldots \ldots \ldots \ldots \ldots \ldots \ldots \ldots \ldots \ldots \ldots \ldots \ldots \ldots \ldots, 12$

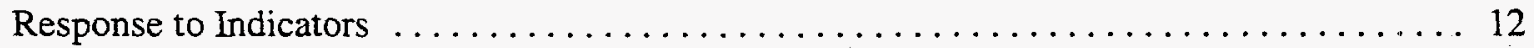

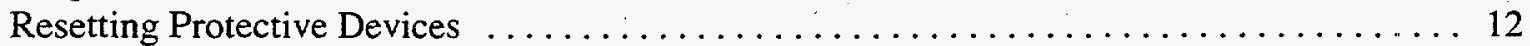

Authority to Operate $\ldots \ldots \ldots \ldots \ldots \ldots \ldots \ldots \ldots \ldots \ldots \ldots \ldots \ldots \ldots \ldots \ldots \ldots \ldots \ldots \ldots \ldots, 12$

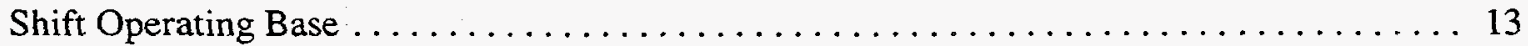

Potentially Distractive Materials and Devices $\ldots \ldots \ldots \ldots \ldots \ldots \ldots \ldots \ldots \ldots \ldots, \ldots \ldots$

CHAPTER III

CONTROL AREA ACTIVITIES

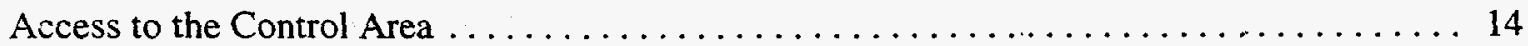

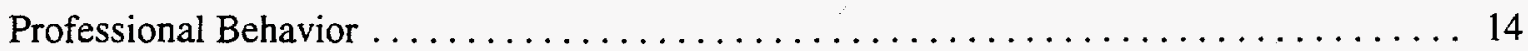

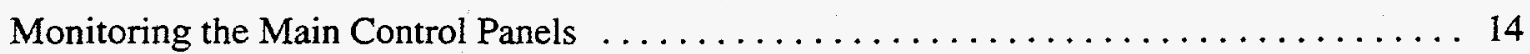

Control Room Operator Ancillary Duties . . . . . . . . . . . . . . . . . . . . . . . 15

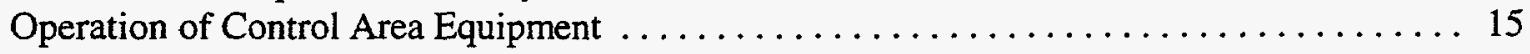




\begin{tabular}{||c|c|c|c|}
\hline \multicolumn{4}{|c|}{ CONDUCT OF OPERATIONS • NATIONAL SYNCHROTRON LIGHT SOURCE } \\
\hline Number: BNL-44403 & Revision 2 & Effective: $1 / 4 / 98$ & Page 3 of 50 \\
\hline
\end{tabular}

\section{CHAPTER IV \\ COMMUNICATIONS}

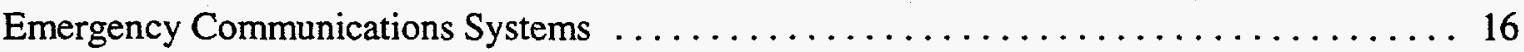

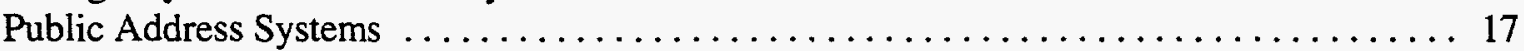

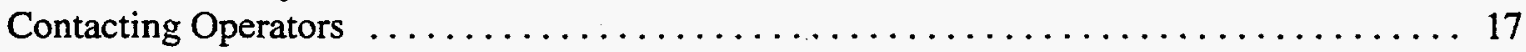

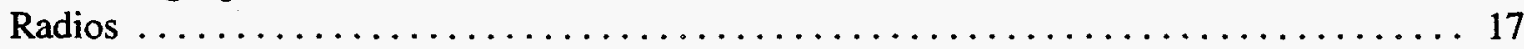

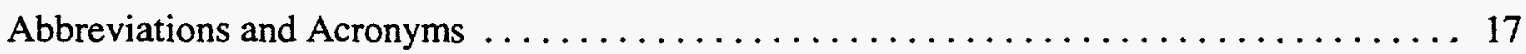

Oral Instructions and Information Communication $\ldots \ldots \ldots \ldots \ldots \ldots \ldots \ldots \ldots \ldots \ldots \ldots$

\section{CHAPTER V \\ CONTROL OF ON-SHIFT TRAINING}

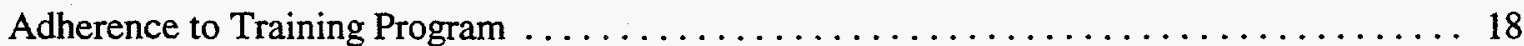

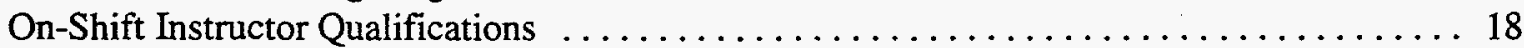

Qualified Operator Supervision \& Control of Trainees $\ldots \ldots \ldots \ldots \ldots \ldots \ldots \ldots \ldots \ldots$

Operator Qualification Program . . . . . . . . . . . . . . . . . . . . . . . 19

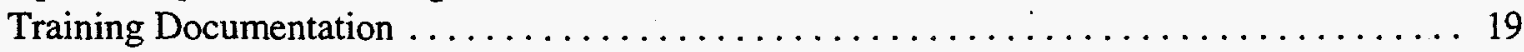

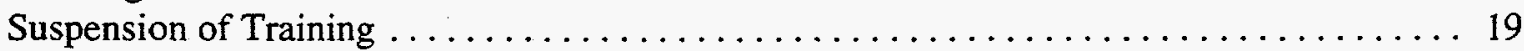

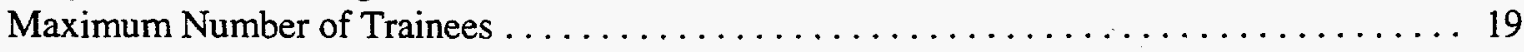

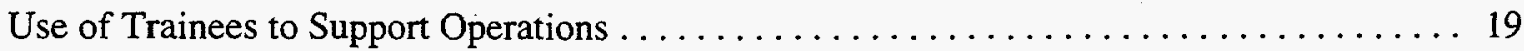

CHAPTER VI

INVESTIGATION OF ABNORMAL EVENTS

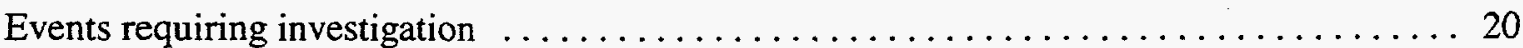

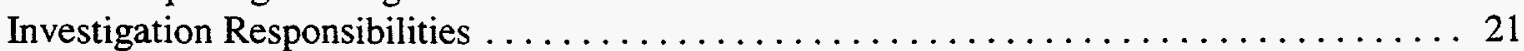

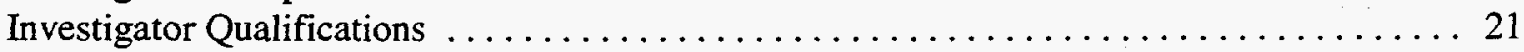

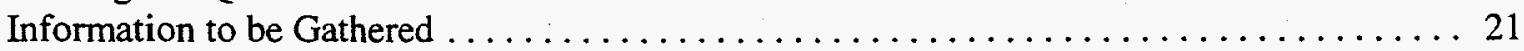

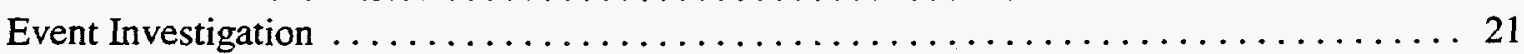

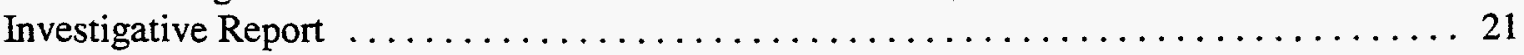

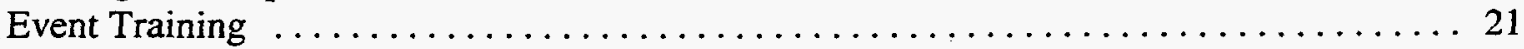

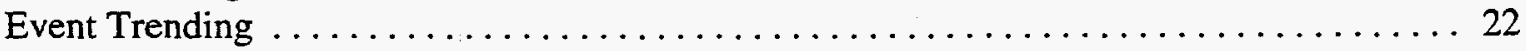

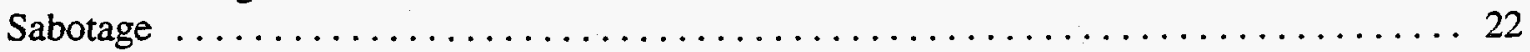

\section{CHAPTER VII}

NOTIFICATIONS

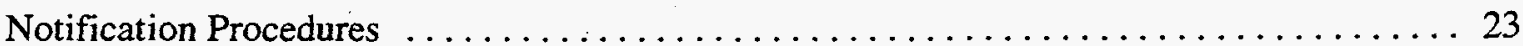

Notification Responsibility ..................................... 24

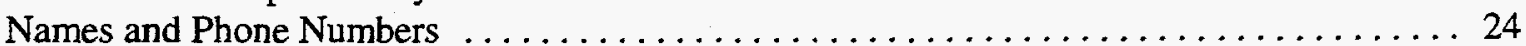

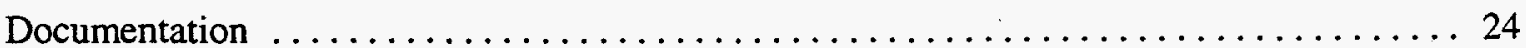

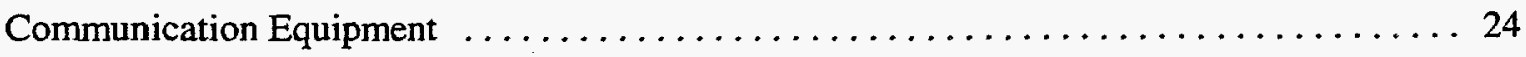




\begin{tabular}{||c|c|c|c|}
\hline \multicolumn{4}{|c|}{ CONDUCT OF OPERATIONS — NATIONAL SYNCHROTRON LIGHT SOURCE } \\
\hline Number: BNL-44403 & Revision 2 & Effective: $1 / 4 / 98$ & Page 4 of 50 \\
\hline
\end{tabular}

\section{CHAPTER VIII \\ CONTROL OF EQUIPMENT AND SYSTEM STATUS}

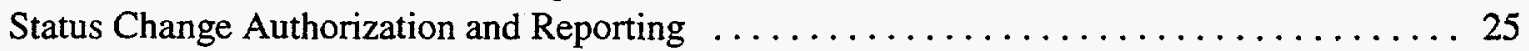

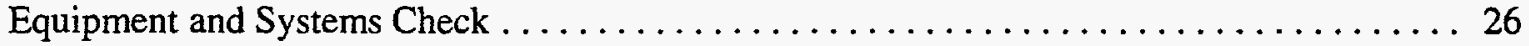

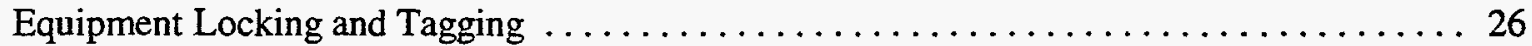

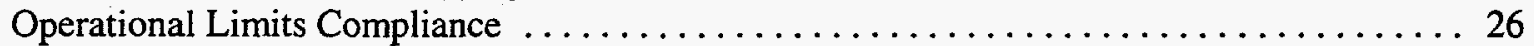

Equipment Deficiency Identification and Documentation $\ldots \ldots \ldots \ldots \ldots \ldots \ldots \ldots \ldots$

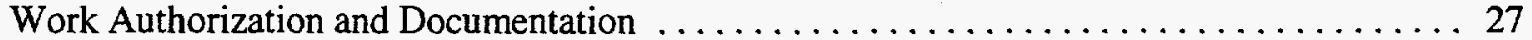

Equipment Post-Maintenance Testing and Return to Service $\ldots \ldots \ldots \ldots \ldots \ldots \ldots \ldots$

Alarm Status . . . . . . . . . . . . . . . . . . . . . . . . . . . . . . . . . . 27

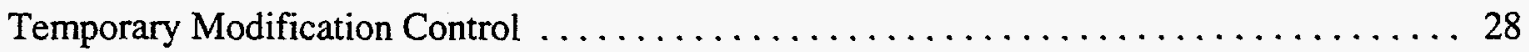

Distribution and Control of Equipment and System Documents $\ldots \ldots \ldots \ldots \ldots \ldots \ldots$

\section{CHAPTER IX \\ LOCKOUTS AND TAGOUTS}

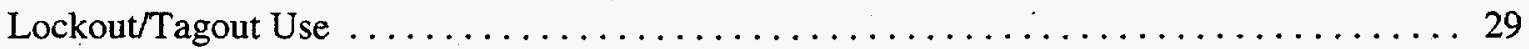

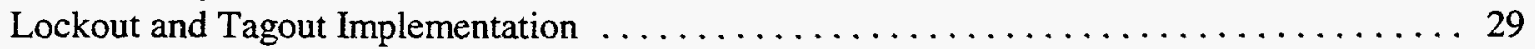

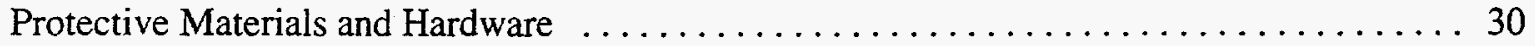

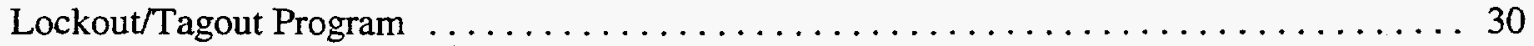

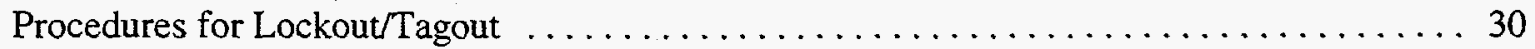

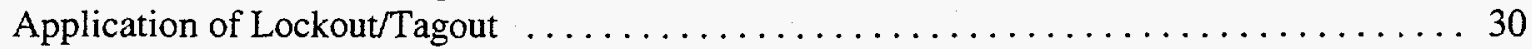

Testing or Positioning of Equipment or Components $\ldots \ldots \ldots \ldots \ldots \ldots \ldots \ldots \ldots \ldots$

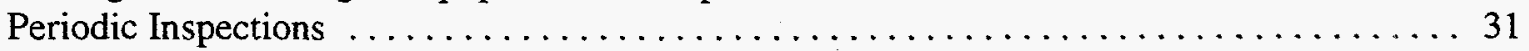

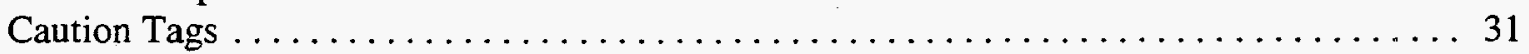

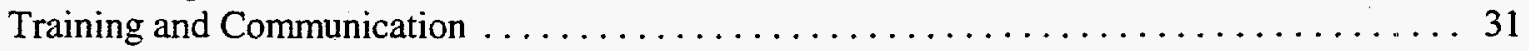

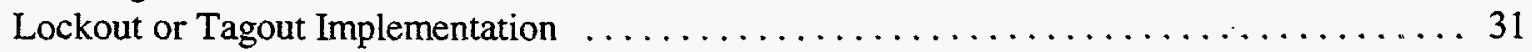

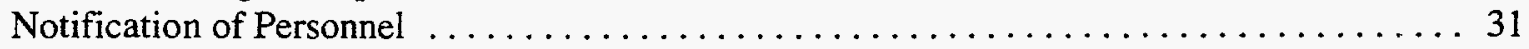

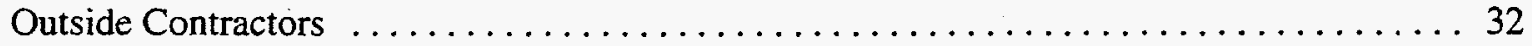

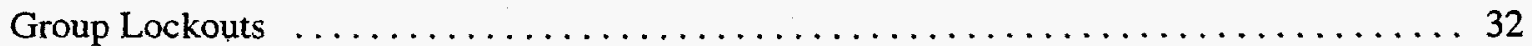

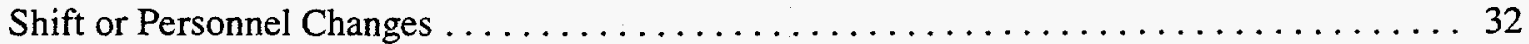

\section{CHAPTER X \\ INDEPENDENT VERIFICATION}

Components Requiring Independent Verification $\ldots \ldots \ldots \ldots \ldots \ldots \ldots \ldots \ldots \ldots \ldots$

Occasions Requiring Independent Verification $\ldots \ldots \ldots \ldots \ldots \ldots \ldots \ldots \ldots \ldots \ldots \ldots \ldots \ldots \ldots$

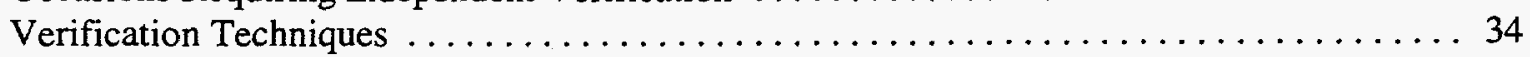




\begin{tabular}{|c|c|c|c|}
\hline \multicolumn{4}{|c|}{ CONDUCT OF OPERATIONS • NATIONAL SYNCHROTRON LIGHT SOURCE } \\
\hline Number: BNL-44403 & Revision 2 & Effective: $1 / 4 / 98$ & Page 5 of 50 \\
\hline
\end{tabular}

\section{CHAPTER XI \\ LOGKEEPING}

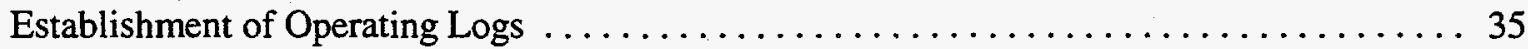

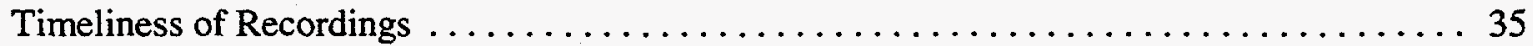

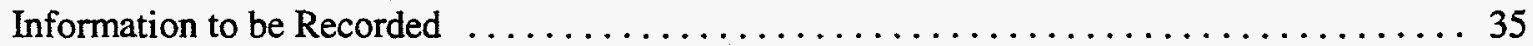

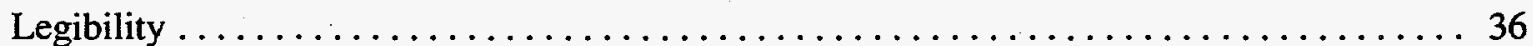

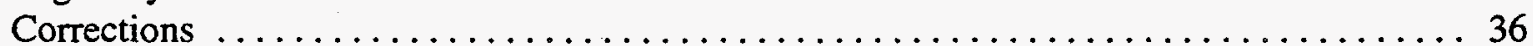

Log Review ........................................... 36

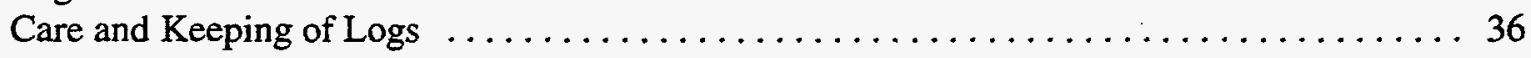

CHAPTER XII

OPERATIONS TURNOVER

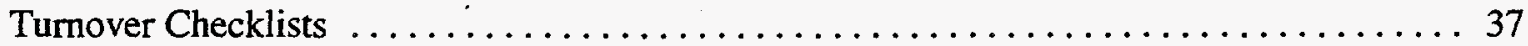

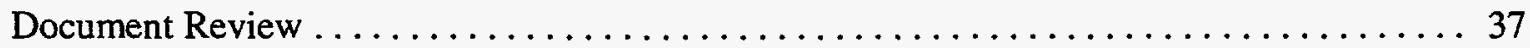

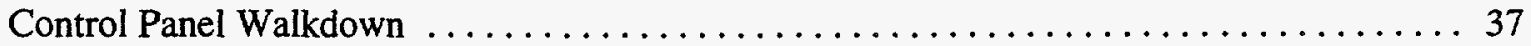

Discussion and Exchange of Responsibility .......................... 38

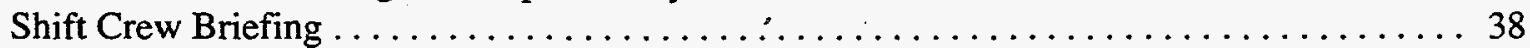

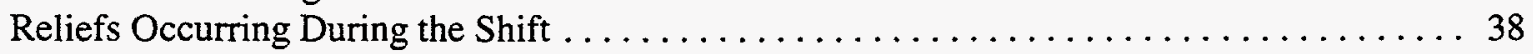

CHAPTER XIII

OPERATIONS ASPECTS OF FACILITY PROCESS CONTROL

Operator Responsibilities . . . . . . . . . . . . . . . . . . . . . . . . . . . . . . . . 39

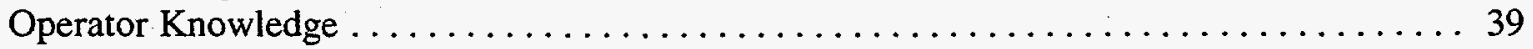

Operator Response To Process Problems ............................... 39

Communication Between Operators and Process Personnel ................... 39

\section{CHAPTER XIV \\ REQUIRED READING}

File Index

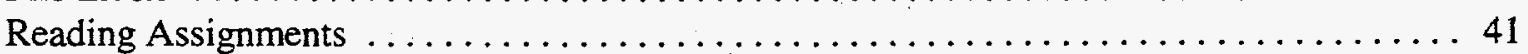

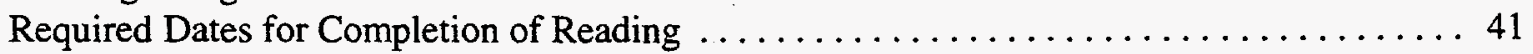

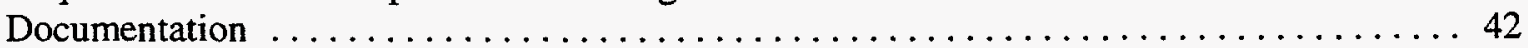

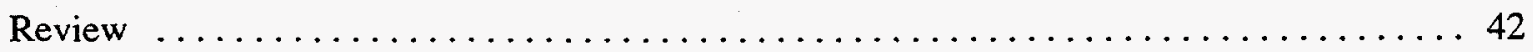

CHAPTER XV

TIMELY ORDERS TO OPERATORS

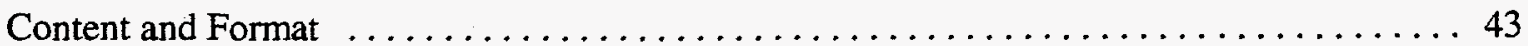

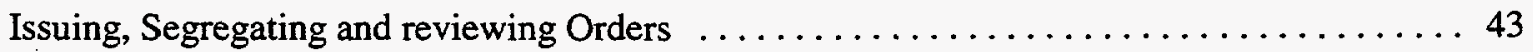

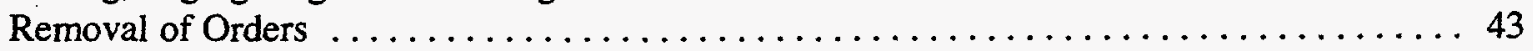




\begin{tabular}{|c|c|c|c|}
\hline \multicolumn{4}{|c|}{ CONDUCT OF OPERATIONS • NATIONAL SYNCHROTRON LIGHT SOURCE } \\
\hline Number: BNL-44403 & Revision 2 & Effective: $1 / 4 / 98$ & Page 6 of 50 \\
\hline
\end{tabular}

\section{CHAPTER XVI \\ OPERATIONS PROCEDURES}

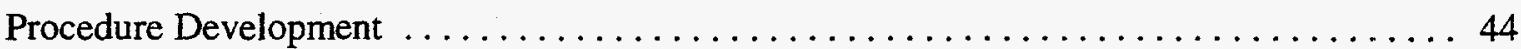

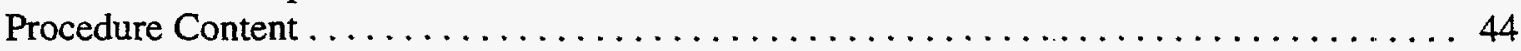

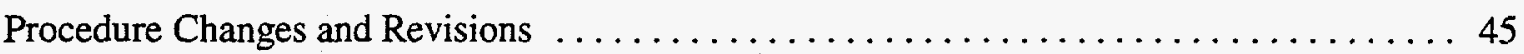

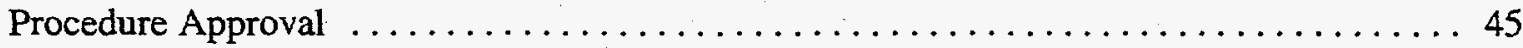

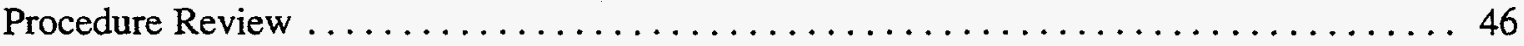

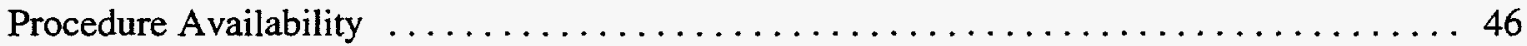

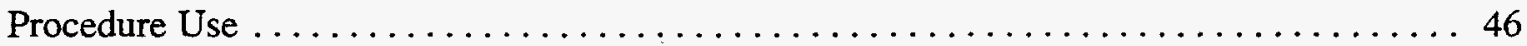

CHAPTER XVII

OPERATOR AID POSTING

Operator Aid Development . . . . . . . . . . . . . . . . . . . . . . . . . . . . 47

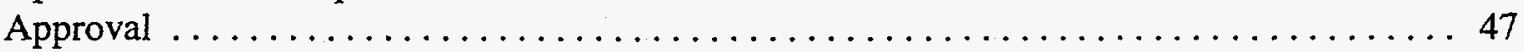

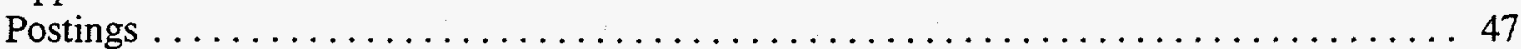

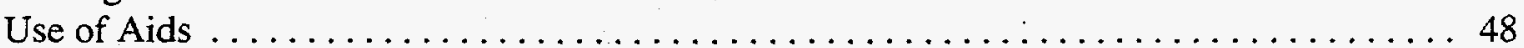

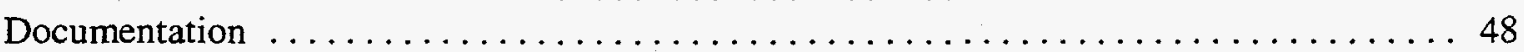

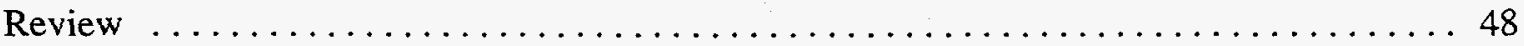

CHAPTER XVIII

EQUIPMENT PIPING AND LABELING

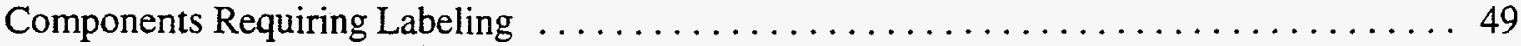

Label Information . . . . . . . . . . . . . . . . . . . . . . . . . . . 50

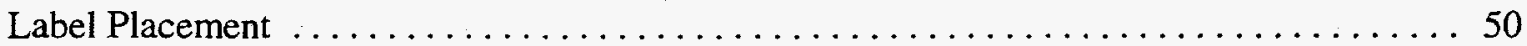

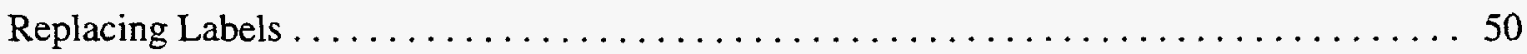




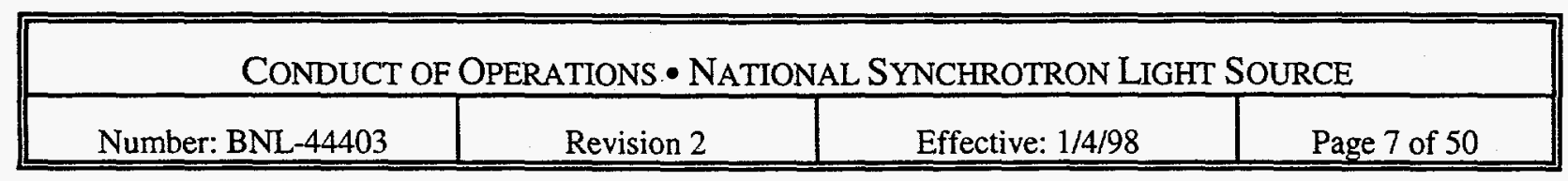

\author{
CONDUCT OF OPERATIONS \\ National Synchrotron Light Source \\ Brookhaven National Laboratory
}

\title{
INTRODUCTION
}

DOE Order 5480.19 To improve the quality and uniformity of operations at the Department of Energy's facilities, the DOE issued Order 5480.19 "Conduct of Operations Requirements at DOE facilities." This order recognizes that the success of a facilities mission critically depends upon a high level of performance by its personnel and equipment. This performance can be severely impaired if the facility's Conduct of Operations pays inadequate attention to issues of organization, safety, health, and the environment. These guidelines are Brookhaven National Laboratory's and the National Synchrotron Light Source's acknowledgment of the principles of Conduct of Operations and the response to DOE Order 5480.19.

Because of the great diversity of the facilities operated by DOE and its contractors, Order 5480.19 calls for "A graded approach... to assure that the depth of detail required and the magnitude of resources expended for operations are commensurate with each facilities programmatic importance and potential environmental, safety and health impact." Further, "The guidelines are written to be flexible, so that they encompass the range from large, permanent DOE test or production facilities to small research or testing facilities..." and "It is expected that facilities may use different approaches or methods than those defined in the guidelines, but facilities are expected to meet the intent of these guidelines." DOE5480.19 does not directly address technical aspects of equipment operation as these are "...facility specific, requiring unique direction." In applying DOE Order 5480.19 to the NSLS, this facility has used the "Graded Approach" to comply with the general nature of the Orders requirements.

\section{Characteristics of the National Synchrotron Light Source}

The worlds foremost facility for scientific research using $\mathrm{x}$-rays, ultraviolet radiation and infrared radiation is operated by the National Synchrotron Light Source (NSLS) Department. In a single year, about 2,200 researches from more than 450 institutions come to use the worlds largest source of synchrotron light. Industry is well represented among the users, with about 50 companies carrying out research at the NSLS. Guest researches often work in collaboration with staff scientists at the Light Source, performing a wide range of innovative experiments in physics, chemistry, biology, materials science and various technologies.

Two storage rings at the NSLS circulate bunches of electrons, at 800 million electron-volts for research in the vacuum ultraviolet portion of the electromagnetic spectrum, and at 2.5 to 2.8 billion electron-volts for research in the $\mathrm{x}$-ray portion of the spectrum. Synchrotron radiation is produced by electrons traveling at nearly the speed of light as they pass through the storage ring bending magnets. Radiation is emitted in an intense, fan-like beam, tangential to the bending arc and travels through ports in the NSLS storage rings to experimental beam lines. Since each port supports one to three beam lines, the 47 ports in the two NSLS storage rings can support as many as 100 simultaneous experiments. 


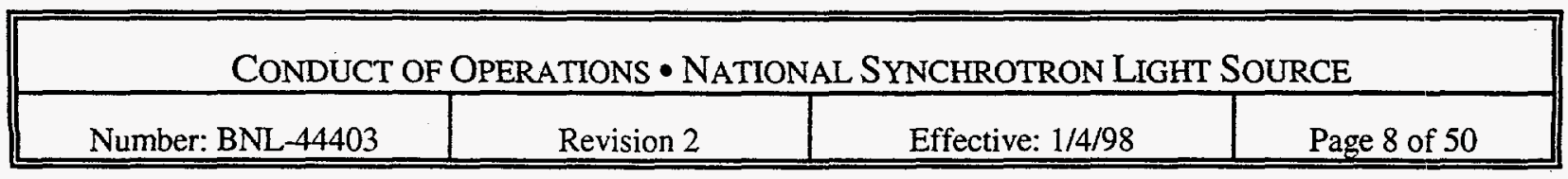

\section{CHAPTER I}

\section{OPERATIONS ORGANIZATION AND ADMINISTRATION}

\section{A. INTRODUCTION}

The organization and administration of the NSLS operations, is intended to achieve a high level of safety and performance, that is accomplished through effective implementation and control of operational activities. Operational policies and procedures recognize that protecting the environment, and assuring safety and efficient operations, are compatible goals. Such policies and procedures reflect the standards of excellence used in operating this facility. These policies set up the lines of responsibility for normal and ernergency operations, and provide a method to monitor and assess performance. This chapter discusses the policies, resources, and assessment needed in operations.

\section{B. DISCUSSION}

The NSLS achieves a high level of excellence by having the operations management establish high levels of performance. Management communicates these standards to the NSLS staff. Personnel are well trained and their performance monitored. The Head of the Operations Group, establishes standards, defines goals, and determines the responsibilities of the operational staff. The operations staff provides input and feedback to standards and training. Management uses reports and goals to measure performance. Personnel are held accountable for their performance through supervisory counseling, performance appraisals, and when necessary, administrative action. Remedial training is provided, if appropriate.

\section{GUIDELINES}

\section{Operational Policies}

The overall organization of the NSLS is shown in the NSLS "Safety and Environmental Administrative Polices and Procedures Manual" (SEAPPM) and the NSLS Facilities Manual. Each person involved in the operation is shown and to whom that person is primarily responsible. Alternative supervision is also shown. The NSLS Chairman periodically reviews the organization chart to insure its accuracy. The organization chart reflects all modes of operation in the NSLS. The NSLS SEAPPM includes responsibilities for visitors, users, students and non-BNL personnel.

There are written operational procedures for all activities that could adversely impact operations safety or quality. The NSLS Operations Group procedures and policies are in accordance with those incorporated in the NSLS "Safety Analysis Reports" (BNL 49214, 51584, 52205, 52205 Addendum).

Formal training is provided for critical or especially complex procedures. General 


\begin{tabular}{|c|c|c|c|}
\hline \multicolumn{4}{|c|}{ CONDUCT OF OPERATIONS • NATIONAL SYNCHROTRON LIGHT SOURCE } \\
\hline Number: BNL-44403 & Revision 2 & Effective: $1 / 4 / 98$ & Page 9 of 50 \\
\hline
\end{tabular}

operations training is provided through On-The-Job training, supervised by experienced personnel selected by NSLS management and staff supervisors in conjunction with the NSLS Training Coordinator. Procedures and training requirements are maintained in the NSLS Facility Manual and included in the NSLS Training Plan.

Visiting scientists and associates must read the "NSLS Users' Guide", view a training video on General Employee Radiation Training (GERT) and NSLS Safety. They must pass a written examination on GERT and NSLS Safety and complete an NSLS Safety Orientation Certification Form. A radiation badge may be issued and access granted to the Controlled Area after all of the above requirements are completed.

Operational goals are defined at weekly meetings of the experimental users. Performance standards set, monitored and recorded at these meetings. Monthly charts of machine performance are kept and published in the National Synchrotron Light Source Annual Report.

A fault reporting system accounts for all machine downtime. These reports are reviewed biweekly by the engineering and technical staff. Daily performance of the storage rings is reviewed by the Ring Managers and the Operations Group Section Head. Computer History programs allow Ring Managers to review machine operational parameters in detail and allow diagnosis of problems.

\section{Resources}

The NSLS Chairman assures that there are sufficient resources for safe and efficient operation of the facility. The NSLS management considers long-range staffing needs and develops plans to implement them. These plans are consistent with the allotted funding and the NSLS's mission.

NSLS Machine Operators and Operations Coordinators operate on a shift basis with minimal overtime.

Technical staff are assigned equipment responsibilities (see NSLS Electrical System Responsibilities SLS-08.2-1-1 and NSLS Mechanical System Responsibilities SLS-08.2-3-1) and are called in to repair or service equipment as needed.

\section{Monitoring of Operating Performance}

Real-time machine parameters and 24-hour performance histories are displayed on TV sets distributed throughout the NSLS and also on sets located in the BNL's Directors office, the physics building and the cafeteria. TV displayed data and messages may be accessed via telephone both on and off site.

All operating problems or conditions are recorded in the operators log book. Machine faults 


\section{CONDUCT OF OPERATIONS • NATIONAL SYNCHROTRON LIGHT SOURCE}

are recorded and reported in writing to the responsible engineer or technician daily. Operations Coordinators monitor the NSLS experimental program via log entries, experimental approval forms and regular tours. Management holds monthly reviews to determine performance trends.

NSLS has an ALARA program and a routine radiation monitoring system is in place. Environmental safety and health inspections are carried out every three months, reports of which are sent to all management levels. Safety interlock inspectons are completed under accordance with NSLS SEAPPM NS 1.5.3.

\section{Accountability}

All personnel are held accountable for their performance. NSLS management performs evaluations of all personnel to determine if problems exist. Retraining or administrative action is considered for personnel involved in significant or frequent violations of NSLS policies and/or procedures.

\section{Management Training}

The NSLS Training Policy, Responsibilities and Requirements are included in the NSLS Facility Manual. The NSLS management and supervisors in conjunction with the NSLS Training Coordinator determines which BNL and NSLS-specific training must be given to support operational activities. The NSLS management and supervisors will attend training determined by the NSLS Chairman.

\section{Planning for safety}

All operational activities are carried out under the constraints of the NSLS "Safety Analysis Report" (SAR) and according to the Operational Safety Limits. All personnel are expected to understand the safety policies required by the SAR and the NSLS SEAPPM. Guidelines for safety review of experimental beamlines are included and a formal, documented review process is carried out for all beamlines. Individual experiments are reviewed and approved by NSLS staff via a safety approval form.

Operations Coordinators are trained to implement NSLS policies for beamline operations. All experimental beamline users view a safety video and read and sign-off on safety documentation prior to being authorized for radiation badges and access to the experimental floor. 


\begin{tabular}{|c|c|c|c|}
\hline \multicolumn{4}{|c|}{ CONDUCT OF OPERATIONS • NATIONAL SYNCHROTRON LIGHT SOURCE } \\
\hline Number: BNL-44403 & Revision 2 & Effective: $1 / 4 / 98$ & Page 11 of 50 \\
\hline
\end{tabular}

\section{CHAPTER II}

\section{SHIFT ROUTINES \& OPERATING PRACTICES}

\section{A. INTRODUCTION}

This chapter describes some important aspects of routine operations and practices. Chapters III, Control Area Activities, and Chapter IV, Communications, contain the related guidelines.

\section{B. DISCUSSION}

Effective monitoring of equipment is necessary to detect abnormal conditions or adverse trends. Monitoring allows actions to be taken before the equipment malfunctions. Notifying the Operations Group Section Head promptly of unusual or unexpected situations will help to assure that attention is given to any problems. The Head of the Operations Group is responsible for NSLS operations and formally transfers authority to operate to the Operations Supervisor. The Head of the Operations Group decides on the response to abnormal conditions and reviews and approves any special tests. NSLS personnel must follow the proper practices for industrial safety, radiological protection and quality assurance.

\section{GUIDELINES}

\section{Status Reports}

Operators must monitor the various instruments that describe the NSLS status. Operators follow chapter NS1.1.0 "NSLS Occurrence Reporting System" of the NSLS SEAPPM. If the occurrence involves personnel safety, the NSLS Safety Coordinator and/or Safety Officer shall be notified. Operators must notify the Head of the Operations Group and appropriate Ring Manager when the machine has been down for more than two hours.

Operators must make out a fault report for all unscheduled downtime. The Operators Supervisor prepares status reports on downtime and machine performance.

\section{Safety Practices}

Operators must fulfill all ES\&H requirements including that the operation is in compliance with the Operational Safety Limits. General ES\&H requirements are given in the BNL ES\&H Manual, NSLS-specific requirements are given in the NSLS SEAPPM.

\section{Inspections}

Operations Coordinators carry out regular tours of the experimental areas at least once per 


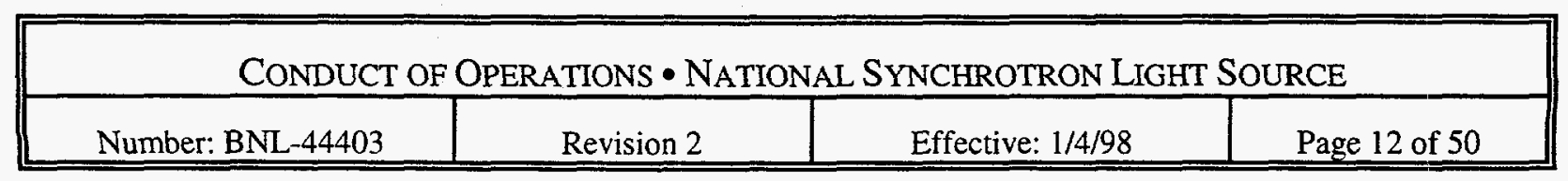

shift. Checks are made to insure beamline compliance with the "Experimental Safety Approval Form" and the "Beamline Safety Checklist". Beamline status is monitored both locally and by computer. Regular ( 3 month) safety tours are carried out for all NSISS areas, and followed up to ensure compliance.

\section{Personnel Protection}

The Operations Group Section Head in conjunction with the NSLS Safety Officer reviews operational practices to maintain personnel exposures to hazards "As Low As Reasonably Achievable" (ALARA). NSLS has an ALARA policy in compliance with DOE Order 5480.11

The Operations Group Section Head in conjunction with the NSLS Training Coordinator, determines which BNL safety courses and NSLS-specific courses operational personnel must take. All Operators and Coordinators receive "Radiological Worker I Training" (RWT002) and "Hazcom Training" (IND200). Operations Coordinators receive training in radiation monitoring and carry out routine surveys of beamline radiation levels. BNL S\&EP personnel assigned to the NSLS carry out routine radiation surveys and perform surveys at the request of the Operations Group and NSLS Safety Staff.

There is an ongoing radiation monitoring process for the experimental floor using Thermoluminescence Dosimeters (TLD's) and chipmunk devices which are read and reviewed monthly by the NSLS safety officers and BNL Safety and Environmental Protection Division (S\&EP) personnel attached to NSLS.

\section{Response to Indicators}

Operators must report and log any abnormal operations, systems or equipment failures. A fault report must be written, and affected personnel must be made aware of the potential consequences of these problems. The Operations Group Section Head and Ring Managers are responsible for scheduling corrective actions and notifying all effected personnel of operational problems.

\section{Resetting Protective Devices}

Protective devices are installed to protect personnel and equipment from operating beyond there design limits. Protective devices may only be reset after establishing the cause of exceeding the device limit. Corrective action by the operator or technical staff is taken and reported as needed. Major occurrences are reported and investigated as required by NSLS SEAPPM NS1.1.0 "Occurrence Reporting System".

\section{Authority to Operate}

The NSLS Chairman gives the authority for operations to the Head of the Operations Group. 


\begin{tabular}{||c|c|c|c|}
\hline \multicolumn{4}{|c|}{ CONDUCT OF OPERATIONS • NATIONAL SYNCHROTRON LIGHT SOURCE } \\
\hline Number: BNL-44403 & Revision 2 & Effective: $1 / 4 / 98$ & Page 13 of 50 \\
\hline
\end{tabular}

The Head of the Operations Group gives the authority to operate to the Operations Supervisor but maintains the responsibility for all NSLS operations. The Operators and Coordinators are responsible for operating the NSLS safely and efficiently by adhering to operational procedures, operational safety limits, and NSLS quality assurance requirements. Any work by support groups which might impact the operation of the accelerators shall be approved by the on-duty Operator.

8. Shift Operating Base

The NSLS Control Room is the base of NSLS accelerator operational activities.

9. Potentially Distractive Materials and Devices

The Operations Supervisor must approve the use of computerized, written, audio, or visual material not having to do with operations. 


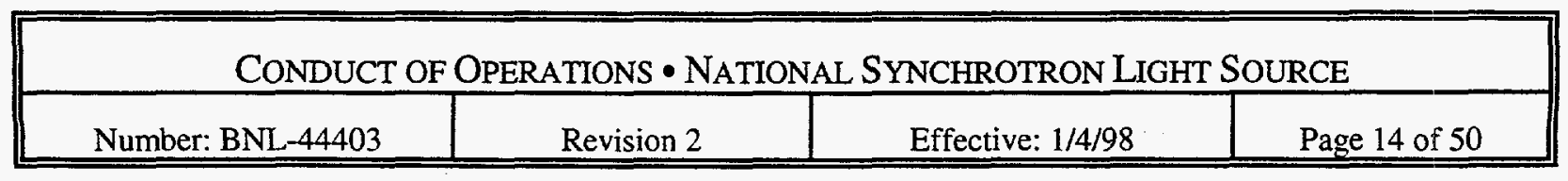

\section{CHAPTER III}

\section{CONTROL AREA ACTIVITIES}

\section{A. INTRODUCTION}

This chapter discusses the control area activities that help to achieve safe and efficient operations.

\section{B. DISCUSSION}

The control area (i.e. control room) is the coordination point for all important operations. Operators should not be overburdened with administrative responsibilities. Access to the control area should be limited so that operators are not distracted from properly monitoring and adjusting facility parameters.

\section{GUIDELINES}

\section{Access to the Control Area}

The NSLS Control Room is a posted restricted areas with access limited to authorized personnel. The Operators Supervisor or on duty Operator grants entry to the control room and has the authority to restrict access.

Personnel not specifically trained and authorized are restricted from operating the controls. Students, visitors and trainees must be made aware of safe working habits before entering the control room.

\section{Professional Behavior}

The Operations Group Section Head and Operators are responsible for enforcing professional behavior in the control room. Personnel disrupting operations will be removed from the control room. Visitors accompanied by authorized personnel will be admitted access to the control room at the discretion of the on-duty Operator.

\section{Monitoring the Main Control Panels}

Operators monitor, prepare printouts and save files of the main operating parameters and also major changes in operational requirements. Operators $\log$ and respond to malfunctions and alarms according to established procedure, so that steps can be taken to correct problems.

NSLS machine status is displayed on TV sets located above the operator console, individual 


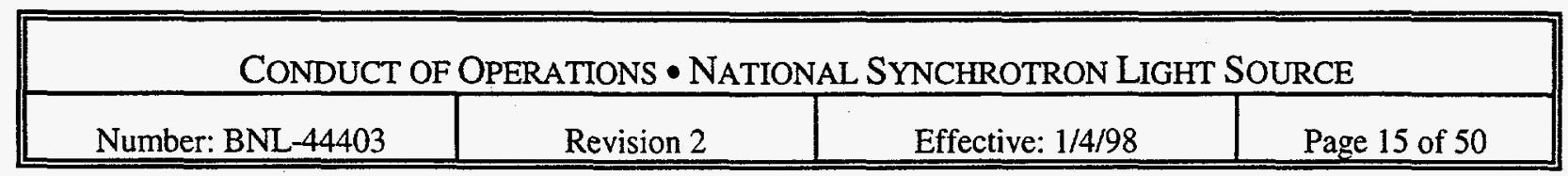

equipment status is available via the operations computer terminals. All machine set points are stored in memory in the computer and can be restored or compared to the current set points. All equipment is individually protected to "failsafe" and does not depend upon computer intervention.

\section{Control Room Operator Ancillary Duties}

The Operations Group Section Head is responsible for reviewing operator tasks to assure that operators are not performing duties that could interfere with the proper monitoring of operations. Operators perform administrative tasks only when operating conditions permit. An Operations Coordinator with required minimum training and authorized to operate the machine takes over the operational function when necessary.

\section{Operation of Control Area Equipment}

Only operators trained and authorized by the Operations Group Section Head may operate the NSLS controls. A list of authorized operators is posted in the control room and maintained in the NSLS Facility Manual. New operating personnel receive operations training through a documented On-The-Job (OTJ) training program. Experienced operators supervise new operating personnel until the Head of the Operations Group formally approves their ability to operate the controls.

In addition Ring Managers, Physicists, and Engineers may operate equipment that they have the responsibility for, and perform machine studies, in accordance with NSLS Conduct of Operations and with the knowledge of the on-duty operator. 


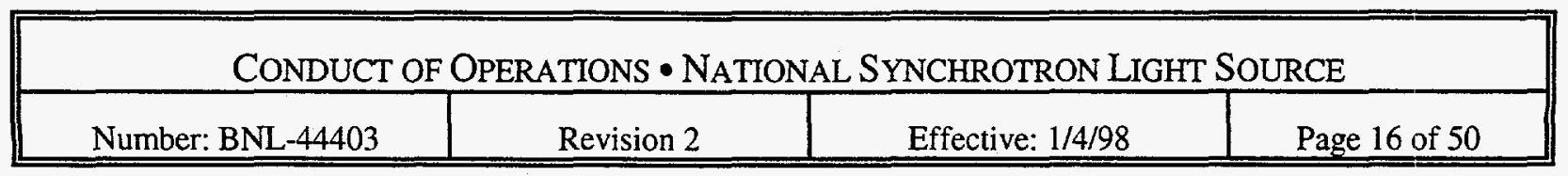

\section{CHAPTER IV}

\section{COMMUNICATIONS}

\section{A. INTRODUCTION}

Communications should be reliable and accurate when transmitting information within the NSLS, Communications systems should be designed to insure that information is readily accessible to NSLS staff and users.

\section{B. DISCUSSION}

Oral and computer communications are the primary means of sending operations information. Since accurate communication is essential for safe and efficient operation, guidance in its use is necessary. Operators use the facilities audio and visual warning devices to alert personnel to abnormal or emergency conditions. These communications are controlled, to insure that they do not detract from normal operations and are available in an emergency. Specific information on communication procedures must be given to outside users.

\section{GUIDELINES}

\section{Emergency Communications Systems}

The NSLS control room has a BNL telephone system to contact BNL emergency response personnel. The emergency number is extension 2222 or 911 and is posted in the control room. The backup system for emergency response is through activation of the manual fire-alarm station. Communication systems are tested to insure they are functional.

The NSLS on-duty operator is the "Local Emergency Coordinator" for the NSLS facility as specified in the NSLS "Emergency Plans" contained in the Facility Manual.

The BNL "Plectron Warning System" sounds in the control room and gives information on BNL emergencies, evacuations, weather alerts, etc. This system is operated by the BNL Safeguards and Security Division.

The automatic fire alarm system sounds warning bells in all NSLS areas in the event of an emergency requiring an emergency evacuation. This system can be activated manually. A public address system is used by the operator to reinforce the evacuation. The control room can override telephone access to the PA System when needed. The Plectron Warning System, fire alarms and the PA system are tested periodically. 


\begin{tabular}{||c|c|c|c|}
\hline \multicolumn{4}{|c|}{ CONDUCT OF OPERATIONS • NATIONAL SYNCHROTRON LIGHT SOURCE } \\
\hline Number: BNL-44403 & Revision 2 & Effective: $1 / 4 / 98$ & Page 17 of 50 \\
\hline
\end{tabular}

2. Public Address Systems

A public address system is used to give information regarding machine operations. The microphone for this system is situated in the Control Room and is controlled by the on-duty Operator.

Excessive use of the PA system for contacting department personnel and unnecessary announcements should be avoided.

For normal communications, pocket pagers, facility telephones and E-mail are used.

\section{Contacting Operators}

Staff normally contact Operators by the facility telephone. The Operators extension is 2550 . Experimenters may contact the Operations Coordinators by pocket pager \#5824 or extension 5046. Portable radios are utilized by the Operations Coordinators to maintain contact with the control room and each other.

Emergency information is relayed to the control room via the BNL "Plectron Warning System".

4. Radios

Portable radios are used throughout the NSLS by the operations staff to maintain contact with the control room and each other. Channel F1 is dedicated to operations, channel F2 is used by other groups.

\section{Abbreviations and Acronyms}

Operators and Coordinators should use only commonly known abbreviations and acronyms in communications, these include equipment names as designated in the computer data base.

\section{Oral Instructions and Information Communication}

Oral instructions should be clear and concise, and the sender and intended receiver should be readily identifiable. Instructions involving the operation of equipment, should be repeated by the receiver when necessary to insure that the instructions are understood. 


\begin{tabular}{|c|c|c|c|}
\hline \multicolumn{4}{|c|}{ CONDUCT OF OPERATIONS • NATIONAL SYNCHROTRON LIGHT SOURCE } \\
\hline Number: BNL-44403 & Revision 2 & Effective: $1 / 4 / 98$ & Page 18 of 50 \\
\hline
\end{tabular}

\section{CHAPTER V}

\section{CONTROL OF ON-SHIFT TRAINING}

\section{A. INTRODUCTION}

The primary mode of training for operating the NSLS is through on-the-job training. Training must be carefully supervised and controlled to avoid mistakes in operations. This chapter discusses the NSLS's training requirements.

\section{B. DISCUSSION}

On-the-job training, is that part of the training in which the trainee receives hands-on experience with the NSLS controls and equipment. This instruction is supervised by experienced operations personnel. The Head of the Operations Group, in conjunction with the NSLS Training Coordinator, is responsible for determining the training methods, materials, and documentation according to BNL training polices and standards.

\section{GUIDELINES}

\section{Adherence to Training Program}

The Head of the Operations Group, in conjunction with the NSLS Training Coordinator, determines the training requirements, duration of training and when an operator is qualified to operate the NSLS without direct supervision. In addition, a checklist shall be used to assure completion of training requirements.

Trainees are required to familiarize themselves with the NSLS Facility Manuals, NSLS systems, policies and procedures. The Head of the Operations Group selects which NSLS-specific, BNL-wide, or other training programs personnel must attend to be qualified to operate or use the facility.

The Head of the Operations Group may authorize training exemptions based on an assessment of personnel experience. The NSLS Operator and Coordinator training requirements and exemptions are documented in the NSLS Facility Manual consistent with the requirements of the NSLS Training Plan.

\section{On-Shift Instructor Qualifications}

The Head of the Operations Group, authorized by the NSLS Chairman, has the authority to operate the NSLS. The Head of the Operations Group determines who is qualified to instruct the trainees. Instructor qualifications will be documented and retained according to the 


\section{CONDUCT OF OPERATIONS • NATIONAL SYNCHROTRON LIGHT SOURCE}

NSLS Training Plan.

\section{Qualified Operator Supervision \& Control of Trainees}

Qualified operators supervise training whenever trainees operate equipment, insuring that errors are not made that could degrade NSLS safety or operation. Information recorded by trainees is reviewed by qualified Operators.

\section{Operator Qualification Program}

BNL Training Policy, Standards and Guidelines require that the NSLS provide a statement of training requirements by functional job, and facility and work location.

The Operator Qualification Program shall be approved by the Control Room Supervisor. The NSLS Training Coordinator and the Control Room Supervisor shall coordinate any changes in the program.

\section{Training Documentation}

BNL Training Policy requires that all BNL training shall be documented using the Training Course Description form, BNL F2942, or its equivalent.

Completion of the Operator and Coordinator training program shall be documented according to NSLS SEAPPM section NS 7.1.0.

\section{Suspension of Training}

Training shall be immediately suspended in the event of an abnormal occurrence or emergency condition.

\section{Maximum Number of Trainees}

There shall be no more than one new Operator trainee and no more than two new Operations Coordinator trainees on any given shift.

\section{Use of Trainees to Support Operations}

The Operators Supervisor decides when an operator trainee, under normal operating conditions, is permitted to perform certain procedures by himself/herself. 


\begin{tabular}{||c|c|c|c|}
\hline \multicolumn{4}{|c|}{ CONDUCT OF OPERATIONS • NATIONAL SYNCHROTRON LIGHT SOURCE } \\
\hline Number: BNL-44403 & Revision 2 & Effective: $1 / 4 / 98$ & Page 20 of 50 \\
\hline
\end{tabular}

\section{CHAPTER VI}

\section{INVESTIGATION OF ABNORMAL EVENTS}

\section{A. INTRODUCTION}

BNL's policy for investigating and reporting abnormal events is defined in BNL Environmental Safety and Health (ES\&H) Standards Manual, 1.1.0, "Occurrence Reporting System". The objectives of this program are:

- That abnormal events (Emergency, Unusual and Off-Normal occurrences and Near-Miss situations) are thoroughly investigated to assess their impacts on operations.

- That occurrences meeting certain criteria are promptly reported to BNL and DOE management.

- That root causes are identified.

- That corrective actions are identified and taken to prevent recurrence

\section{B. DISCUSSION}

This facility has formal training to assure that abnormal events (occurrences) are recognized, reported, investigated, and corrected. These events can be created by both BNL employees and outside users. All persons must be made aware of what is an abnormal event and what actions must be taken when they occur. Abnormal events are occurrences that could:

- Affect the health and safety of the public, employees or guests.

- Have an adverse effect on the environment.

- Affect the operations and intended purpose of the NSLS.

- Result in loss or damage to property.

\section{GUIDELINES}

\section{Events requiring investigation}

NSLS "Safety and Environmental Administrative Policies and Procedures Manual" (SEAPPM), Chapter NS1.1.0 "NSLS Occurrence Reporting System" covers criteria for when to perform an investigation.

NSLS SEAPPM Chapter NS 1.1.0 section 8.0 lists specific events requiring an investigation.

BNL ES\&H Standard 1.1.0 "Occurrence Reporting System" section 8.8.2, lists criteria for "near miss", emergency, unusual or off-normal conditions. 


\begin{tabular}{|c|c|c|c|}
\hline \multicolumn{4}{|c|}{ CONDUCT OF OPERATIONS • NATIONAL SYNCHROTRON LIGHT SOURCE } \\
\hline Number: BNL-44403 & Revision 2 & Effective: $1 / 4 / 98$ & Page 21 of 50 \\
\hline
\end{tabular}

2. Investigation Responsibilities

Staff appointed by the NSLS Chairman shall act as Facility Managers for the NSLS Department. These people are listed in the BNL SEAPPM 1.1.0 and are also posted in the NSLS Control Room.

\section{Investigator Qualifications}

The NSLS Chairman in conjunction with the Head of the Operations Group is responsible for appointing knowledgeable persons from the facilities staff and BNL staff safety professionals to investigate events.

BNL staff members from the Safety and Environmental Protection Division, BNL Quality Assurance Office, and Laboratory Operations Support Office are available to assist in investigations.

\section{Information to be Gathered}

NSLS personnel, together with the professional staff of the BNL S\&EP Division will collect all necessary information to complete an investigation of an event. This information should include the initial condition of the facility, statements of Operators and other personnel, logs and other pertinent documents.

\section{Event Investigation}

Investigations of events shall follow the approved format specified in BNLES\&H Standards Manual, 1.1.0 "Occurrence Reporting System".

\section{Investigative Report}

The investigative report shall follow the approved format specified in BNLES\&H Standards Manual, 1.1.0 "Occurrence Reporting System".

\section{Event Training}

Information collected by NSLS personnel and by the Program Review Office of the BNL S\&EP Division will be used for "lessons-learned" feedback to NSLS personnel, so that operations, maintenance and training can be improved.

NSLS Safety officers and Operational personnel develop and carry out drills dealing with emergency situations that might reasonably be expected to occur during NSLS operations. 


\begin{tabular}{|c|c|c|c|}
\hline \multicolumn{4}{|c|}{ CONDUCT OF OPERATIONS • NATIONAL SYNCHROTRON LIGHT SOURCE } \\
\hline Number: BNL-44403 & Revision 2 & Effective: $1 / 4 / 98$ & Page 22 of 50 \\
\hline
\end{tabular}

8. Event Trending

The Program Review Office of the BNL Safety and Environmental Protection Division, tracks all occurrences and issues reports to NSLS Safety personnel for review and analysis.

9. Sabotage

NSLS SEAPPM chapter 1.1.0, section 8.5,provides guidance on Sabotage under the heading of Criminal Acts. The NSLS Operations staff will immediately report any suspected sabotage to the BNL Safeguards and Security Division. 


\begin{tabular}{|c|c|c|c|}
\hline \multicolumn{4}{|c|}{ CONDUCT OF OPERATIONS • NATIONAL SYNCHROTRON LIGHT SOURCE } \\
\hline Number: BNL-44403 & Revision 2 & Effective: $1 / 4 / 98$ & Page 23 of 50 \\
\hline
\end{tabular}

\section{CHAPTER VII}

NOTIFICATIONS

\section{A. INTRODUCTION}

NSLS management and DOE must be notified promptly of abnormal occurrences to assure that the Laboratory is responsive to public health and safety concerns. This chapter provides guidance to assure the uniformity, efficiency and completeness of these notifications according to the requirements of BNL ES\&H Standards Manual, 1.1.0 "Occurrence Reporting System"

\section{B. DISCUSSION}

Some abnormal events depending on their seriousness, require verbal notification within 15 minutes of categorization as "Emergency Occurrences", and within 2 hours of categorization as "Unusual Occurrences". No verbal notification is required for Off-Normal Occurrences. All DOE reportable events require a written report to DOE management within 24 hours of categorization.

\section{GUIDELINES}

\section{Notification Procedures}

BNL SEAPPM 1.1.0, "Occurrence Reporting System" lists the NSLS Notification Call List, which includes the Facility Manager and alternates together with their telephone numbers. This information is also posted in the NSLS Control Room.

NSLS SEAPPM 1.1.0, "Occurrence Reporting System" identifies the events and conditions requiring notification, together with notification time requirements.

The NSLS Emergency Plan is maintained in the NSLS Facility Manual, and describes notification procedures in the event of an emergency.

NSLS policy dictates that the Operations Group Section Head and appropriate Ring Manager are notified when the machine has been down for longer than two hours. The on-duty Operator normally decides when to activate an equipment responsibilities call-in list. 


\begin{tabular}{||c|c|c|c|}
\hline \multicolumn{4}{|c|}{ CONDUCT OF OPERATIONS • NATIONAL SYNCHROTRON LIGHT SOURCE } \\
\hline Number: BNL-44403 & Revision 2 & Effective: $1 / 4 / 98$ & Page 24 of 50 \\
\hline
\end{tabular}

2. Notification Responsibility

The NSLS Operations Group Section Head is responsible to ensure that those individuals listed on the appropriate call-in list have indeed been notified and that any requirernents for notification have been complied with.

\section{Names and Phone Numbers}

The names and phone numbers of the NSLS Facility Manager and alternates are listed in the BNL SEAPPM, 1.1.0 "Occurrence Reporting System" and posted in the NSLS Control Room.

The names and phone numbers of NSLS personnel required to be notified in the event of an emergency, are listed in the NSLS Emergency Plan maintained in the Facility Manual.

Equipment responsibilities call-in lists are maintained in the NSLS control room. They are broken down by equipment grouping, and contain names of primary and alternative personnel, phone numbers and pager numbers.

\section{Documentation}

The BNL Program Review Office of the S\&EP Division maintains a central file of BNL Occurrence Reports.

The S\&EP Division documents all hazardous oil or chemical spills and/or radiological airborne emissions and notifies the appropriate Local and State authorities.

The on-duty Operator and/or the Operations Coordinator logs all abnormal conditions or problems.

\section{Communication Equipment}

The on-duty Operator will use the BNL telephone system to notify NSLS management of an occurrence. The NSLS Facility Manager or his alternates will notify the S\&EP Program Review Office by telephone and DOE through the established network. 


\begin{tabular}{||c|c|c|c||}
\hline \multicolumn{4}{|c|}{ CONDUCT OF OPERATIONS • NATIONAL SYNCHROTRON LIGHT SOURCE } \\
\hline Number: BNL-44403 & Revision 2 & Effective: $1 / 4 / 98$ & Page 25 of 50 \\
\hline
\end{tabular}

CHAPTER VIII

CONTROL OF EQUIPMENT AND SYSTEM STATUS

\section{A. INTRODUCTION}

Good operating practices will maintain the NSLS's configuration within its design limits and provide the Operators with knowledge of the status of the equipment and systems.

\section{B. DISCUSSION}

Operators must be aware of how the equipment and systems function. Operators and Coordinators also must be aware of operational safety and reliability limits. Changes in equipment and system configuration must be communicated to the affected operating personnel, by noting these changes in the operations logbook(s), or by using other methods to allow Operators to review the changes.

The status of the equipment and systems is controlled according to NSLS procedures, which includes ensuring compliance with operational safety limits before changes are made to operational modes, including the removal or restoration of equipment to service. Identification and documentation of equipment deficiencies is important to assure safe and reliable operation.

\section{GUIDELINES}

\section{Status Change Authorization and Reporting}

Modifications meeting the criteria specified in BNL ES\&H Standard Manual 1.3.2 "Operational Readiness Review" shall be submitted for formal Operational Readiness evaluation.

Changes to major equipment and systems shall be via a NSLS documented review.

Non-safety operational changes may be authorized by the Operations Group Section Head or Ring Managers. Equipment group personnel must notify the on-duty Operator of any equipment changes that may effect the performance of the NSLS. Operators insure that changes in the NSLS configuration and status are communicated to all operations personnel and must document those changes in the NSLS operations log. Computer "Restore" files are used to place the NSLS equipment in a baseline configuration for startup.

The configuration of experimental beamlines is reviewed and documented by the NSLS Beamline Review Committee. The Beamline Review Committee works with the ES\&H committee and the Safety Officer, reporting to the NSLS Associate Chairman. 
CONDUCT OF OPERATIONS • NATIONAL SYNCHROTRON LIGHT SOURCE

Upon completion, each experimental beamline is reviewed by the Safety Officer before permission to operate is given. Individual experiments are all reviewed prior to operation via a Safety Approval Form review.

\section{Equipment and Systems Check}

Equipment operational checks are carried out after shutdowns for maintenance or repairs. These tests ensure operation at design levels. Checklists are used as needed or appropriate. Ring Managers are responsible for insuring adequate commissioning time and training after equipment or system changes.

Configuration control is exercised on the beamlines through intervention and oversight by the Operations Coordinators and Safety Officer. Prior to operation after a lock-out condition, a detailed Beamline Checklist must be completed and signed before the beamline is enabled.

Work on the beamline hardware or interlocks requires a lock-out and the completion of an NSLS Work Permit and if required, an interlock test. An interlock test must be completed if the integrity of the interlock system has been changed. A checklist is used to record the results of the tests.

\section{Equipment Locking and Tagging}

All operations personnel shall have training on BNL ES\&H Standards Manual 1.5.1 "Lockout/Tagout Requirements". Special locks and tags are available in the NSLS Control Room. Use of locks and tags are recorded in a log book maintained in the control room, this $\log$ shall be audited on a regular basis.

A system of Operations Coordinator controlled locks exists to lock out equipment deemed by the Safety Officer to present a hazard during open access to the storage rings or beamline enclosures.

\section{Operational Limits Compliance}

All NSLS equipment is designed to be self limiting, and as such cannot cause a safety hazard or equipment damage. However, to operate within the design parameters of the NSLS Safety Review Analysis, and also to keep radiation exposures "As Low As Reasonably Achievable" (ALARA) certain Operational Safety Limits (OSL) have been established and are posted in the NSLS Control Room. The on-duty Operator is responsible for maintaining these operational limits.

\section{Equipment Deficiency Identification and Documentation}

Equipment and system faults are noted in the operations $\log$ and a fault report sent to the 


\begin{tabular}{||c|c|c|c|}
\hline \multicolumn{4}{|c|}{ CONDUCT OF OPERATIONS • NATIONAL SYNCHROTRON LIGHT SOURCE } \\
\hline Number: BNL-44403 & Revision 2 & Effective: $1 / 4 / 98$ & Page 27 of 50 \\
\hline
\end{tabular}

responsible group supervisor or engineer. Monthly and yearly fault charts are generated by the Operators Supervisor.

6. Work Authorization and Documentation

Maintenance and equipment upgrades are planned on a monthly basis, work schedules are drawn up by the Maintenance Coordinators and approved by the Operations Group Section Head. These schedules are distributed to all operational personnel and posted in the NSLS Control Room. Long range shutdowns are planned by the Ring Managers in conjunction with the Chief Mechanical and Electrical Engineers.

Preventive maintenance is performed on a work order basis generated by a preventive maintenance computer program.

Experiments operate under the limits imposed by the Safety Approval Form, signed by the Safety Officer. The NSLS work permit program is used to monitor and control all work in progress on beamlines which may affect safety.

The NSLS Ring Work Permit Program is used to monitor and control all work in progress, on the LINAC/Booster, X-Ray \& VUV Ring, that may affect the safety of each system.

\section{Equipment Post-Maintenance Testing and Return to Service}

Post-maintenance equipment checks are performed by the responsible equipment groups prior to operational startup by the on-duty Operator. These checks ensure that the startup is performed in an efficient manner and the storage rings operate at their design levels.

The on-duty Operator checks and records certain operational outputs versus equipment set points as part of the machine turn-on procedure. Computer "Save and Restore" programs are used to set the machine parameters to a baseline configuration and other programs check equipment for errors.

Following any work on the safety system the entire system is rigorously functionally tested and documented by the Safety Officer.

Work which may affect beamline and ring configuration is monitored by the work permit system and the beamline checklists. They are revised and approved prior to experimental beamline restart.

\section{Alarm Status}

Operators and Coordinators are trained to respond to all NSLS equipment and system alarms. After establishing and/or correcting the cause, the Operator, Coordinator or responsible technician may reset equipment alarms. 


\begin{tabular}{||c|c|c|c|}
\hline \multicolumn{4}{|c|}{ CONDUCT OF OPERATIONS - NATIONAL SYNCHROTRON LIGHT SOURCE } \\
\hline Number: BNL-44403 & Revision 2 & Effective: $1 / 4 / 98$ & Page 28 of 50 \\
\hline
\end{tabular}

The Fire alarm status is latched at the NSLS display panel, and at the BNL firehouse. The Operators and Coordinators are trained in the NSLS Emergency Plan.

NSLS experimental beamline have safety system hardware which display the beamline's system status. Faults are latched and indicated by lights, requiring review and resetting by the safety personnel according to a detailed procedure.

\section{Temporary Modification Control}

Temporary modifications must be approved by the Operations Group Section Head and/or Ring Managers. They shall be logged in the operations log book(s) by the on-duty Operator and/or Operations Coordinator. All modifications to safety systems must be approved and documented by the NSLS Safety Officer.

Updated operating procedures must be documented and reviewed by the on-duty Operator and/or Operations Coordinator.

\section{Distribution and Control of Equipment and System Documents}

The NSLS Master File maintained in the NSLS Design Room contains the latest design documents including drawings and specifications, design review documents, procurement and incoming test documents, and non-conforming material control documents.

The NSLS Facility Manual maintained in the NSLS Control Room contains the latest NSLS operations policies, procedures and revisions. These documents are controlled and tracked. 


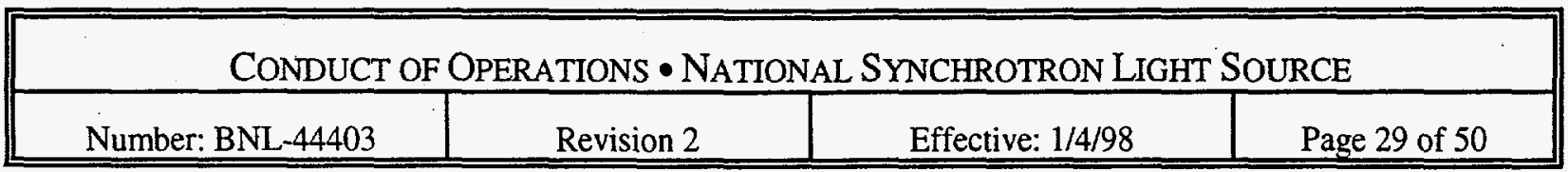

\section{CHAPTER IX}

\section{LOCKOUTS AND TAGOUTS}

\section{A. INTRODUCTION}

This chapter provides a method to control equipment through tagging and/or locking. These actions protect personnel from injury and protect equipment from damage. Accidental operation of equipment during normal operation, servicing, or maintenance activities has the potential to cause personal injury, or equipment damage. The Lockout/Tagout program allows workers to be sure that equipment has been removed from service and later restored to operation.

\section{B. DISCUSSION}

Tagout is the application of a warning tag on an energy-isolating device. Tagout shows that the energy-operating device and the equipment it controls must not be operated. Lockout is the placement of a lock or similar mechanism on an energy-isolating device. The NSLS shall perform Lockout/Tagout according to BNL ES\&H Standards Manual, 1.5.1 "Lockout/tagout Requirements" and NSLS SEAPPM 1.5.1. Personnel who perform Lockout/Tagout shall be trained in these requirements and the specific requirements of the NSLS.

\section{GUIDELINES}

\section{Lockout/Tagout Use}

BNL ES\&H Standards Manual 1.5.1. "Lockout/Tagout Requirements" provides guidance on the use of Lockout and Tagout devices.

NSLS SEAPPM NS1.5.1 "Lockout/Tagout Requirements" gives NSLS specific requirements.

Personnel working at the NSLS shall use Lockout and Tagout devices to isolate energy sources when required. Locks and tags are available from the NSLS Control Room, where use is logged and audited. Only those individuals trained in the use of lockout/tagout, are allowed to implement lockout procedures.

\section{Lockout and Tagout Implementation}

BNL ES\&H Standards Manual 1.5.1 "Lockout/Tagout Requirements" provides guidance on the implementation of Lockout and Tagout procedures.

NSLS SEAPPM 1.5.1 "Lockout/Tagout Requirements" gives NSLS specific guidance. 


\begin{tabular}{||c|c|c|c|}
\hline \multicolumn{4}{|c|}{ CONDUCT OF OPERATIONS • NATIONAL SYNCHROTRON LIGHT SOURCE } \\
\hline Number: BNL-44403 & Revision 2 & Effective: $1 / 4 / 98$ & Page 30 of 50 \\
\hline
\end{tabular}

Locks are issued to trained NSLS personnel only.

New NSLS equipment shall have lockout capability as appropriate.

\section{Protective Materials and Hardware}

BNL ES\&H Standards Manual 1.5.1 "Lockout/Tagout Requirements" provides guidance on the requirements of lockout and tagout devices including the use of BNL standard locks and tags.

NSLS SEAPPM NS1.5.1 "Lockout/Tagout Requirements" gives NSLS specific guidance. BNL standard locks and tags are provided in the NSLS Control Room.

\section{Lockout/Tagout Program}

BNL ES\&H Standards Manual 1.5.1 "Lockout/Tagout Requirements" establishes the BNL Lockout/Tagout program requirements for all Departments and Divisions.

Details of the NSLS program are given in the NSLS SEAPPM 1.5.1 "Lockout/Tagout Requirements"

\section{Procedures for Lockout/Tagout}

BNL ES\&H Standards Manual 1.5.1 "Lockout/Tagout Requirements" provides generic procedures for Lockout and Tagout.

NSLS SEAPPM 1.5.1 "Lockout/Tagout Requirements" contains NSLS specific procedures.

\section{Application of Lockout/Tagout}

BNL ES\&H Standards Manual 1.5.1 "Lockout/Tagout Requirements" establishes the BNL program for lockout/tagout.

NSLS SEAPPM 1.5.1 "Lockout/Tagout Requirements" contains NSLS specific guidelines for the application and removal of lockout/tagout devices.

\section{Testing or Positioning of Equipment or Components}

Testing or positioning of equipment at the NSLS shall be accomplished only by authorized and trained personnel. 


\begin{tabular}{||c|c|c|c||}
\hline \multicolumn{4}{|c||}{ CONDUCT OF OPERATIONS • NATIONAL SYNCHROTRON LIGHT SOURCE } \\
\hline Number: BNL-44403 & Revision 2 & Effective: $1 / 4 / 98$ & Page 31 of 50 \\
\hline
\end{tabular}

8. Periodic Inspections

The Head of the Operations Group or his designee shall audit the lockout/tagout logbook and outstanding tags. Records will be made available to BNL and DOE auditors.

\section{Caution Tags}

Yellow Caution tags are used at the NSLS to convey information about the status of equipment and to prevent equipment damage, where equipment damage is not a personnel hazard. Standard BNL red tags must be used in all personnel safety lockouts. Standard red and yellow caution tags are available in the NSLS Control Room.

A Caution Tag Operations Policy is available in the NSLS Facilities Manual.

\section{Training and Communication}

NSLS SEAPPM NS 1.5.1 Section 2, "Training Department Certification," establishes the requirements of department training programs for Lockout/Tagout.

BNL Training Policy, Standards and Guidelines apply to all training provided by the Laboratory, Departments, Divisions and facilities, including classroom instruction and on-the-job training.

The Head of the Operations Group in conjunction with the NSLS Training Coordinator is responsible for training NSLS personnel in the requirements of the lockout/tagout program as specified in the NSLS Training Plan. The NSLS Training Coordinator maintains lockout/tagout training records and certifications.

\section{Lockout or Tagout Implementation}

BNL ES\&H Standard Manual 1.5.1 "Lockout/Tagout Requirements" establishes the qualifications for individuals to implement lockout/tagout procedures.

\section{Notification of Personnel}

BNL ES\&H Standards Manual 1.5.1. "Lockout/Tag-out Requirements" establishes generic notification requirements.

Lockout of equipment affecting the performance of the NSLS storage rings must be with the knowledge of the on-duty Operator and noted in the operations logbook. 


\begin{tabular}{|c|c|c|c|}
\hline \multicolumn{4}{|c|}{ CONDUCT OF OPERATIONS • NATIONAL SYNCHROTRON LIGHT SOURCE } \\
\hline Number: BNL-44403 & Revision 2 & Effective: $1 / 4 / 98$ & Page 32 of 50 \\
\hline
\end{tabular}

\section{Outside Contractors}

BNL ES\&H Standards Manual 1.5.1 "Lockout/Tagout Requirements" establishes the responsibilities of Visitors, Contract employees and their BNL coordinates.

\section{Group Lockouts}

BNL ES\&H Standards Manual 1.5.1 "Lockout/Tagout Requirements" establishes generic group lockout requirements.

\section{Shift or Personnel Changes}

BNL ES\&H Standards Manual 1.5.1 "Lockout/Tagout Requirements establishes generic shift and personnel change procedures for lockout/tagout. 


\section{CONDUCT OF OPERATIONS • NATIONAL SYNCHROTRON LIGHT SOURCE}

\section{CHAPTER X}

\section{INDEPENDENT VERIFICATION}

\section{A. INTRODUCTION}

The independent verification program provides a high degree of reliability in the NSLS operation. This chapter describes the important aspects of this program. Other control programs for equipment status are given in chapter VII, Control of Equipment and System Status, and some applications of independent verification are discussed in Chapter IX, Lockouts and Tagouts.

\section{B. DISCUSSION}

Independent verification is the act of checking that a given operation conforms to established operating criteria, as well as checking a components status independently of activities related to establishing the components position. The independent verification program identifies critical components, establishes when independent verification is required, and describes the methods for performing independent verification. Not all components require independent verification because the possibility of improper status may be remote or its effect would not be significant to safe and efficient operation.

\section{GUIDELINES}

\section{Components Requiring Independent Verification}

Systems that present significant personnel hazards (flammable gas, large cryogenic systems, large stored energy systems, radiation shielding, etc.) are reviewed by the NSLS Operations Group Section Head, Engineering Heads, NSLS Safety Committee, Interlock Committee or Beamline Review Committee prior to installation, and are inspected and authorized for operation by the NSLS Safety Officer, after any modifications or extended NSLS shutdown.

The general criteria in deciding if independent verification is warranted are as follows:

a.) Could improper equipment status affect the safety or health of personnel.

b.) Could improper equipment status affect the environment.

c.) Could improper equipment status significantly affect the NSLS performance or cause program loss.

d.) Would improper equipment status be recognized immediately by an operator.

e.) Could significant exposure to radiation or other hazardous substances be received by the person(s) performing the independent verification. 


\begin{tabular}{|c|c|c|c|}
\hline \multicolumn{4}{|c|}{ CONDUCT OF OPERATIONS • NATIONAL SYNCHROTRON LIGHT SOURCE } \\
\hline Number: BNL-44403 & Revision 2 & Effective: $1 / 4 / 98$ & Page 34 of 50 \\
\hline
\end{tabular}

2. Occasions Requiring Independent Verification

Safety systems are checked and authorized by the NSLS Safety Officer after any modification or extended NSLS shutdown. Beamline safety systems are checked and reauthorized by the NSLS Safety Officer on a 6 month basis.

Equipment turn on and performance checks are performed by the responsible technical group personnel, after extended shutdowns and prior to machine startup by the on-duty operator.

\section{Verification Techniques}

Operators, Coordinators and NSLS technical staff are trained in the techniques for verifying the status of all NSLS equipment.

NSLS devices are continuously verified by computer applications programs, software and hardware limits and alarms.

Personnel safety systems have independent hardware and logic to verify that they are in the proper state.

Search and secure procedures, verify that personnel are out of "secured" areas prior to machine startup. The correct procedure is enforced by the safety system logic, which will not allow the safety system "ring secured" reset, if the incorrect procedure is used. Access door positions are monitored by redundant door switches.

Equipment damage protection is verified by means of independent interlocks (for example temperature and water flow). 


\begin{tabular}{||c|c|c|c||}
\hline \multicolumn{4}{|c|}{ CONDUCT OF OPERATIONS • NATIONAL SYNCHROTRON LIGHT SOURCE } \\
\hline Number: BNL-44403 & Revision 2 & Effective: $1 / 4 / 98$ & Page 35 of 50 \\
\hline
\end{tabular}

\section{CHAPTER XI}

\section{LOGKEEPING}

\section{A. INTRODUCTION}

Operations records contain a narrative $\log$ of the NSLS status, and of all events required to reconstruct a history of operations. In this context, logs are defined as a narrative sequence of events or functions performed by the operations staff.

\section{B. DISCUSSION}

Operation logs are established to record the data necessary to provide a history of the NSLS's operation. The scope, type, and amount of data required by management is entered into the logs, including documentation of actions taken, activities completed, and data necessary to reconstruct events. Logs are reviewed to insure they are adequately maintained and that operations personnel are aware of the information in the logs.

\section{GUIDELINES}

\section{Establishment of Operating Logs}

The NSLS operations, beamline operations and target system logs are maintained in the NSLS Control Room and at the target system. Entries are made only by NSLS Operators, Operations Coordinators and qualified Target Watch Operators.

\section{Timeliness of Recordings}

Information is entered promptly or as soon as reasonably possible to prevent inaccuracies. Logkeeping does not take precedence over controlling and monitoring the NSLS.

\section{Information to be Recorded}

All information pertaining to the safe and efficient operation of the NSLS is recorded in the operations logbooks. To aid in reconstructing events, as much information as possible is logged during emergencies and abnormal or unexpected events.

Minimum information required:

- Machine modes for X-Ray/VUV rings, undulators, wigglers and X-5 Target System (e.g. operations, shutdown, maintenance, bunch pattern, system contents, system position, etc.)

- Changes in NSLS operating mode or condition. 


\begin{tabular}{||c|c|c|c|}
\hline \multicolumn{4}{|c|}{ CONDUCT OF OPERATIONS • NATIONAL SYNCHROTRON LIGHT SOURCE } \\
\hline Number: BNL-44403 & Revision 2 & Effective: 1/4/98 & Page 36 of 50 \\
\hline
\end{tabular}

- Record of critical data.

- Abnormal facility configurations.

- Status changes in safety-related or important equipment.

- Occurrences of reportable events.

- Initiation and completion of tests or studies.

- Security, Medical and Fire incidents.

- Shift reliefs and call-ins.

4. Legibility

All log entries must be legible, understandable, and made in pen of a color that can be photocopied.

\section{Corrections}

Incorrect entries are scored with a single line and initialed. Reference to incorrect entries are made in the shift summary.

\section{Log Review}

The operations log book is reviewed daily by the Operations Group Section Head and Supervisor.

7. Care and Keeping of Logs

The Operators Supervisor has the responsibility for filing and storing the logs for the expected life of the facility. Back-logs are available from the Operations Supervisor for review by Operators, Coordinators or staff returning after an absence. 


\begin{tabular}{|c|c|c|c|}
\hline \multicolumn{4}{|c|}{ CONDUCT OF OPERATIONS • NATIONAL SYNCHROTRON LIGHT SOURCE } \\
\hline Number: BNL-44403 & Revision 2 & Effective: $1 / 4 / 98$ & Page 37 of 50 \\
\hline
\end{tabular}

\section{CHAPTER XII}

OPERATIONS TURNOVER

\section{A. INTRODUCTION}

Operations turnover provides oncoming operators with an accurate picture of the overall status of the NSLS. This chapter compliments the guidelines of Chapter II, Operating Practices, and Chapter III, Control Area Activities, and describes the important aspects of good operations turnover.

\section{B. DISCUSSION}

Operations turnover is a critical part of the NSLS's operation. Inaccurate or improper (incomplete) shift turnover can contribute to, or cause safety incidents, so it is essential that operations personnel perform shift turnovers such that an effective transfer of information takes place. Personnel shall not assume operational duties unless they are physically and mentally fit to do so, and until they and the off-going personnel have a high degree of confidence that an appropriate information transfer has taken place.

Oncoming personnel shall review the written (logs, records) and visual (TV displays, oscilloscopes, computer pages and alarm pages) information and receive a verbal briefing before assuming the responsibility of operating the NSLS. Appropriate shift-overlap time must be allowed to accomplish proper information transfer.

\section{GUIDELINES}

\section{Turnover Checklists}

Computer "Save and Restore" files are used to store all machine parameters and are used in place of shift checklists. The on-coming Operator will familiarize himself/herself with the current save and restore files. In addition, each shift logs files used and changes in parameters.

\section{Document Review}

Oncoming Operators use the first several minutes of the shift scanning various TV displays, alarm displays, computer pages and reading the on-going log to familiarize themselves with the current operating conditions.

\section{Control Panel Walkdown}

As part of operator take-over, the on-coming Operator and Coordinator reviews the machine status and previous operational history displayed on TV monitors in the control room. 


\section{Discussion and Exchange of Responsibility}

Before taking responsibility for operating the NSLS, the on-coming Operator and Coordinator(s) will sit with the out-going Operator and Coordinator(s) to ensure that he/she is fully cognizant of the operating conditions. The Operator and Coordinator(s) will then sign in the log.

\section{Shift Crew Briefing}

The on-coming Machine Operator and Operations Coordinator is given a verbal briefing by the out-going Machine Operator/Operations Coordinator, covering what has occurred since he/she was last on shift. In addition, the on-coming Operator and Coordinator will review and sign the log.

\section{Reliefs Occurring During the Shift}

The on-duty Operator may be relieved from the control room by the Operations Supervisor, Operations Group Section Head, a qualified Operator or a qualified Operations Coordinator, cognizant with the operating conditions of the facility.

The on-duty Operations Coordinator may be relieved by the Operations Supervisor, a qualified Coordinator or a qualified Operator.

The on-coming Operator or Coordinator is given a verbal briefing by the out-going Operator or Coordinator when a relief occurs during the shift. 


\begin{tabular}{|c|c|c|c|}
\hline \multicolumn{4}{|c|}{ CONDUCT OF OPERATIONS • NATIONAL SYNCHROTRON LIGHT SOURCE } \\
\hline Number: BNL-44403 & Revision 2 & Effective: $1 / 4 / 98$ & Page 39 of 50 \\
\hline
\end{tabular}

\section{CHAPTER XIII}

\section{OPERATIONS ASPECTS OF FACILITY PROCESS CONTROL}

\section{A. INTRODUCTION}

This chapter discusses the importance of process control systems when used as part of NSLS operations.

\section{B. DISCUSSION}

Process control operations must be understood by the Operators and Coordinators. They also must understand and maintain the safe handling of chemicals and gases.

\section{GUIDELINES}

\section{Operator Responsibilities}

The Operations Coordinators, who have the responsibility for safety on the experimental floor, are trained to monitor systems and respond to adverse situations in those systems. Examples are the hydrogen target, the cryogenic facility, the water treatment facility, the liquid nitrogen storage facility and beamline safety systems.

\section{Operator Knowledge}

Training of the Operations Coordinators is accomplished through formal BNL and NSLS training in HAZCOM. Radiation Worker Training, Hydrogen Target Training and Materials Handling. In addition on-the-job training takes place for machine support systems, hazardous waste control, liquid nitrogen system operation, etc. Training is documented and recorded by the NSLS Training Coordinator.

\section{Operator Response To Process Problems}

NSLS Operators and Operations Coordinators are trained to make appropriate responses to out of normal events or problems. The response may be following specific procedures, shutting down systems or equipment. If necessary, additional expert assistance is obtained through a call-in list. These events are logged in the operations log in the NSLS Control Room.

\section{Communication Between Operators and Process Personnel}

Fault reports are generated by the on-duty operator and sent to the appropriate supervisor 


\begin{tabular}{||c|c|c|c|}
\hline \multicolumn{4}{|c|}{ CONDUCT OF OPERATIONS • NATIONAL SYNCHROTRON LIGHT SOURCE } \\
\hline Number: BNL-44403 & Revision 2 & Effective: $1 / 4 / 98$ & Page 40 of 50 \\
\hline
\end{tabular}

or engineer whenever there is an equipment or system failure. Weekly meetings provide the forum for reporting and analyzing the situations that have arisen. 


\begin{tabular}{|c|c|c|c|}
\hline \multicolumn{4}{|c|}{ CONDUCT OF OPERATIONS • NATIONAL SYNCHROTRON LIGHT SOURCE } \\
\hline Number: BNL-44403 & Revision 2 & Effective: $1 / 4 / 98$ & Page 41 of 50 \\
\hline
\end{tabular}

\author{
CHAPTER XIV \\ REQUIRED READING
}

\title{
A. INTRODUCTION
}

A file of required reading for operations personnel should assure that appropriate individuals are aware of the important information related to job assignments. This chapter describes such a required reading program.

\section{B. DISCUSSION}

NSLS operations personnel receive important information from the Ring and Operations Managers via the Operators Supervisor, who is responsible for distribution of information to the operators.

\section{GUIDELINES}

\section{File Index}

A list of documents maintained in the Operator and Coordinator required reading file include:

- The operational logs.

- The NSLS Conduct of Operations.

- The NSLS Safety and Environmental Administrative Policy and Procedures Manual (SEAPPM).

- Safety requirements (i.e. Emergency Plan - Bldg. 725, Response to emergencies at the NSLS, NSLS policies and procedures).

- X-Ray Tunnel Search, VUV Ring Search and LINAC/Booster Search.

- Operational Bulletins (containing changes in operational procedures and equipment).

- Operational schedules, maintenance and studies schedules.

- The NSLS operational procedures.

\section{Reading Assignments}

Reading assignments are given to the Operators and Operations Coordinators by the Operators Supervisor. Certain assignments require signatures by the Operators and Coordinators to indicate that they have read and understood the document.

\section{Required Dates for Completion of Reading}

The Operator and Coordinator logs must be read by the on-coming shift before relief of the out-going personnel. 


\begin{tabular}{|c|c|c|c|}
\hline \multicolumn{4}{|c|}{ CONDUCT OF OPERATIONS • NATIONAL SYNCHROTRON LIGHT SOURCE } \\
\hline Number: BNL-44403 & Revision 2 & Effective: $1 / 4 / 98$ & Page 42 of 50 \\
\hline
\end{tabular}

Operational Bulletins, information pertaining to operational schedules or changes must be read by the on-coming Operators and Coordinators such that they are fully cognizant with the status of the facility before taking over the shift.

\section{Documentation}

The operations logs must be signed by the on-coming shift personnel after they have read and understood the content.

Certain Operator and Coordinator information documents, and training notes, must be signed by Operators and Coordinators indicating that they have read and understood the content.

The Operations Supervisor assigns required reading to the Operators and Coordinators. A record is kept of all completed reading assignments.

\section{Review}

Periodic reviews of required reading will be made by the Operations Supervisor to ensure that only relevant and up-to-date information is available. 


\begin{tabular}{|c|c|c|c|}
\hline \multicolumn{4}{|c|}{ CONDUCT OF OPERATIONS • NATIONAL SYNCHROTRON LIGHT SOURCE } \\
\hline Number: BNL-44403 & Revision 2 & Effective: $1 / 4 / 98$ & Page 43 of 50 \\
\hline
\end{tabular}

\section{CHAPTER XV}

TIMELY ORDERS TO OPERATORS

\section{A. INTRODUCTION}

There shall be a means for NSLS management to communicate short-term information and administrative instructions to operations personnel. Other ways of directing Operators and Coordinators are discussed in Chapter XVI, Operations Procedures, and Chapter XVI, Operator Aid Postings.

\section{B. DISCUSSION}

The changing requirements of NSLS operations require that there is a program to quickly issue information to operations personnel.

\section{GUIDELINES}

\section{Content and Format}

Special information required on a particular shift is written in the $\log (\mathrm{s})$ or issued as a bulletin by the Operators Supervisor and verbally emphasized during briefing. Operational changes that are expected to become permanent are implemented as soon as possible in the applications software or Facilities Manual. All short-term orders are to be clearly written, dated and properly maintained.

Operations schedules, schedule changes and other operational information is displayed on TV information channels.

\section{Issuing, Segregating and reviewing Orders}

Shift orders are given to the Operators and Coordinators by the Operations Supervisor. Occasionally special instructions are given to the operators by the Operations or Ring Managers. However, these special instructions have the prior approval of the Operations Supervisor.

\section{Removal of Orders}

The Operators Supervisor is responsible for canceling and removing orders that are no longer applicable. The Operations Supervisor periodically reviews operations bulletins and postings to assure that they are current. 


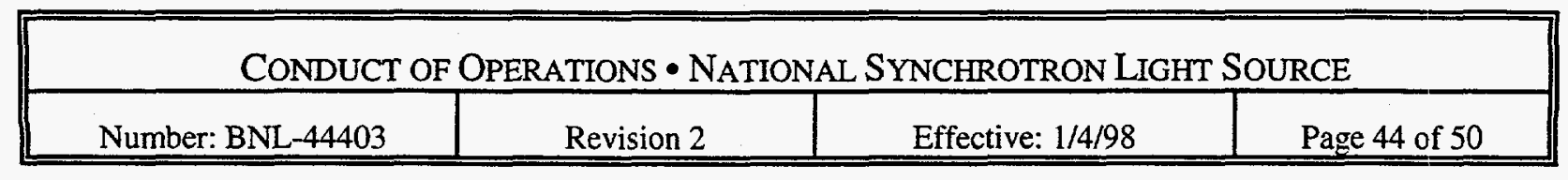

\section{CHAPTER XVI}

\section{OPERATIONS PROCEDURES}

\section{A. INTRODUCTION}

Operations procedures provide specific direction for operating systems and equipment during normal, postulated abnormal and emergency conditions. This chapter describes the important aspects of the development and use of operations procedures.

\section{B. DISCUSSION}

Procedures are a key factor affecting the Operators and Coordinators performance. Operations procedures should be sufficiently detailed so that the required actions can be undertaken without direct supervision. The format may range from detailed step-by-step instructions to general operating guidelines or outlines based on complexity and risk. In all cases, procedures should be written so they can be easily used without making mistakes. To insure that procedures are effective and the best possible instruction is provided, procedures should receive periodic review and feedback.

\section{GUIDELINES}

\section{Procedure Development}

Procedures exist for all normal operations, postulated abnormal and emergency situations. The detail used in the procedures is based on the complexity of the task, the experience and training of the Operators and Operations Coordinators, the frequency of performance and the significance of the consequences of errors. Therefore, procedures can range from step-by-step instruction to general operating guidance.

Most NSLS machine operating procedures are enforced by the computer software applications programs. Needed applications are either developed by the Operations Group or a request is generated by the Operations Group Section Head or Ring Managers to the Computer Systems Group for the required software.

Safety and emergency procedures are developed by NSLS and BNL safety personnel.

\section{Procedure Content}

To provide uniformity in operations procedures, NSLS procedures conform to the following guidelines:

a.) The scope and purpose are clearly defined. 


\begin{tabular}{||c|c|c|c|}
\hline \multicolumn{4}{|c|}{ CONDUCT OF OPERATIONS • NATIONAL SYNCHROTRON LIGHT SOURCE } \\
\hline Number: BNL-44403 & Revision 2 & Effective: $1 / 4 / 98$ & Page 45 of 50 \\
\hline
\end{tabular}

b.) To enhance rapid retrieval, emergency procedures are kept separate from normal operations procedures and are distinguishable by the use of a Red colored binder.

c.) Procedures include information from source documents, such as the NSLS Safety Analysis Report (which is included in the Facilities Manual) and NSLS Machine Operating Limits (posted in the NSLS Control Room). Procedures are dated, when originated or revised, and signed by the Operations Supervisor and the writer.

d.) Warnings, notes and cautions are easily identifiable (printed in bold) and appear on the same page as the step to which they apply.

\section{Procedure Changes and Revisions}

Changes and revisions to procedures are made to reflect current operating practices and requirements. Minor changes to procedures may be hand written and are written on existing procedures without changing the revision level. These changes are approved, initialed and dated by the Operations Supervisor.

Safety and emergency procedures are periodically reviewed (at least annually) by the NSLS Safety Officer to determine if changes are required. Safety and emergency procedures are dated and signed by the NSLS Safety Officer.

The BNL ES\&H Standards Manual and the NSLS SEAPPM are controlled documents. Changes in these procedures are distributed, updated in the NSLS Facility Manual and maintained in the NSLS Control Room.

Operational procedure changes or revisions are noted in the operations $\log (\mathrm{s})$. Operators and Coordinators are briefed on their content and importance.

\section{Procedure Approval}

To ensure accuracy and practicality, operations procedures are reviewed by the Operations Group Section Head and/or Ring Manager(s) before issuance and Operations Supervisor approval.

The Operations Supervisor is responsible for approving all Operations procedures. The Operations Supervisor signs \& dates new and revised operation procedures with red ink. The signature in red ink indicates the original copy.

Safety and/or emergency procedures, must be approved by BNL and/or NSLS safety personnel.

Revisions to the operations procedures receive the same level of approval as the initial versions. 


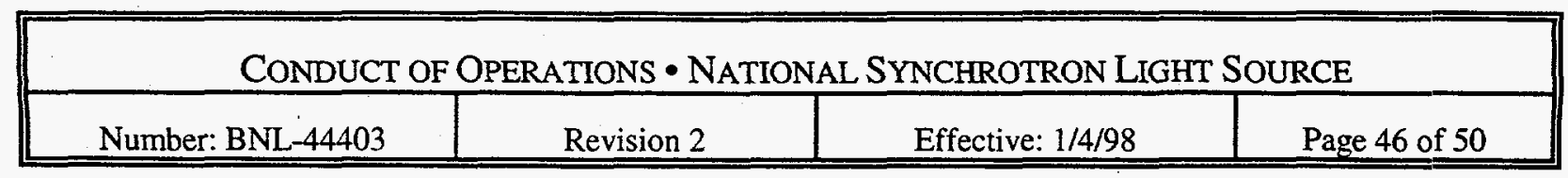

\section{Procedure Review}

Safety and/or emergency procedures, are reviewed by BNL and/or NSLS safety personnel to insure that all aspects of safety and environmental impact have been fully covered before issuance.

Safety and/or emergency procedures are periodically reviewed by the NSLS Safety Officer to ensure they are accurate and up-to-date.

Operational procedures, bulletins, postings, computer applications programs and files are periodically reviewed by the Operators Supervisor to insure that they are accurate and current.

Applicable procedures are reviewed after any abnormal event to ensure their adequacy.

\section{Procedure Availability}

Controlled copies of the BNL ES\&H Standards Manual and NSLS SEAPPM are maintained as part of the NSLS Facility Manual, which is located in the NSLS Control Room. Up-to-date emergency and operational procedures are also included in the NSLS Facility Manual.

Operational applications programs for all areas of the NSLS are available at the operators console and at other conveniently located computer terminals throughout the facility.

\section{Procedure Use}

NSLS operations are conducted according to procedures that reflect the requirements of an experimental user research facility and are carried out in a safe and efficient manner.

Operators and Coordinators take whatever action is necessary during emergency conditions to make the facility safe and to protect equipment, personnel and public safety. These actions are based on training and Operator and/or Coordinator knowledge. Operators and Coordinators need not look up emergency procedures when taking immediate actions in emergency situations, but the procedures must be readily available during and after an occurrence to validate the action. 


\begin{tabular}{|c|c|c|c|}
\hline \multicolumn{4}{|c|}{ CONDUCT OF OPERATIONS • NATIONAL SYNCHROTRON LIGHT SOURCE } \\
\hline Number: BNL-44403 & Revision 2 & Effective: $1 / 4 / 98$ & Page 47 of 50 \\
\hline
\end{tabular}

CHAPTER XVII

OPERATOR AID POSTING

\section{A. INTRODUCTION}

Operator aids should provide information to Operators and Coordinators in performing their duties. An operator aid program should be established to insure that the operator aids posted are current, correct and useful.

\section{B. DISCUSSION}

Operator aids have an important function in the safe operation of the NSLS and may come in many forms: complete or partial copies of procedures, system drawings, hand written notes, computer and TV displays. These postings must reflect the most current information and must not supersede or conflict with any procedure.

\section{GUIDELINES}

\section{Operator Aid Development}

Any NSLS technical staff member may develop an operator aid. However, they must first be approved by the Operations Group Section Head or Operations Supervisor before posting in the control room.

Help aids are developed by the Computer Systems Group, in consultation with the Operations Group Section Head, for the operations applications programs.

Equipment operating aids are developed by technical support groups and reviewed by the group supervisor or responsible engineer.

\section{Approval}

The Operations Supervisor signs and dates operator aid postings in the NSLS Control Room.

\section{Postings}

Operator aids are posted so they do not obscure instruments or controls. Aids are located near the area of their expected use.

Computer "Help" programs are an integral part of the operations applications programs. 


\begin{tabular}{||c|c|c|c|}
\hline \multicolumn{4}{|c|}{ CONDUCT OF OPERATIONS • NATIONAL SYNCHROTRON LIGHT SOURCE } \\
\hline Number: BNL-44403 & Revision 2 & Effective: $1 / 4 / 98$ & Page 48 of 50 \\
\hline
\end{tabular}

4. Use of Aids

Operator aids are used as a convenience and for supplementing approved procedures. They are not used to circumvent approved procedures.

Computer "Help" programs are for information purposes only and do not circumvent the application program.

\section{Documentation}

Operator aid postings are noted in the NSLS operations $\log (\mathrm{s})$.

\section{Review}

During routine inspections of the facility, the Operations Supervisor reviews operator aids to insure that they are accurate, current and necessary. 


\begin{tabular}{|c|c|c|c|}
\hline \multicolumn{4}{|c|}{ CONDUCT OF OPERATIONS • NATIONAL SYNCHROTRON LIGHT SOURCE } \\
\hline Number: BNL-44403 & Revision 2 & Effective: $1 / 4 / 98$ & Page 49 of 50 \\
\hline
\end{tabular}

\section{CHAPTER XVIII}

\section{EQUIPMENT PIPING AND LABELING}

\section{A. INTRODUCTION}

A well established and maintained program for labeling equipment will help to insure that the NSLS and support personnel can identify instrumentation, controls, and equipment. In addition, equipment labeling is required by Operational Safety and Health Administration (OSHA) regulations and various national consensus standards.

\section{B. DISCUSSION}

A good labeling program, understood and maintained by operations and maintenance personnel, enhances the effectiveness of training. It also helps to reduce errors in operations and by maintenance personnel. Errors can result from incorrect identification of equipment and controls. A good labeling program is consistent with the NSLS's ALARA goals because the exposure of personnel to radiation and to hazardous materials is reduced if the operations staff spends less time identifying components.

The labeling program should allow personnel to identify instrumentation, controls and equipment needing labels. In addition to equipment, doors to rooms should be labeled to help NSLS and support personnel to identify rooms, and if applicable, the equipment inside.

\section{GUIDELINES}

\section{Components Requiring Labeling}

All equipment built by the NSLS technical personnel is labeled according to existing laboratory conventions. Commercial built equipment is labeled by the manufacturer.

Emergency exits, fire alarms, fire extinguishers and fire protection equipment are labeled in a standard industrial format.

Circuit breaker panels are labeled so as to designate which circuit they are fed from and what devices they feed.

Cable and wire runs are labeled at each end. Their function and destination are recorded in a cable directory.

Equipment racks are labeled and their location documented. 


\begin{tabular}{||c|c|c|c|}
\hline \multicolumn{4}{|c|}{ CONDUCT OF OPERATIONS • NATIONAL SYNCHROTRON LIGHT SOURCE } \\
\hline Number: BNL-44403 & Revision 2 & Effective: $1 / 4 / 98$ & Page 50 of 50 \\
\hline
\end{tabular}

All transport line and ring magnets, together with their associated power supplies, are labeled with their appropriate mnemonic.

Water piping is labeled with its function and flow direction.

Also included in the facility labeling program are cabinets containing hazardous substances, controlled areas and room doors.

\section{Label Information}

Label information is consistent with the information found in NSLS procedures, drawings and other documentation. Labels are permanently attached and have easy to read information.

\section{Label Placement}

Labels are placed on, or as near as practical, to the controls or equipment being labeled. Labels are oriented so they are easy to read.

\section{Replacing Labels}

The Operations Group Section Head is responsible for insuring that missing or damaged labels, once identified, are promptly replaced. 